University of Windsor

Scholarship at UWindsor

$1-1-1970$

\title{
Determination of total and conjugated glucuronic acid in serum and urine employing a modified naphthoresorcinol reagent.
}

Angelo Mazzuchin

University of Windsor

Follow this and additional works at: https://scholar.uwindsor.ca/etd

\section{Recommended Citation}

Mazzuchin, Angelo, "Determination of total and conjugated glucuronic acid in serum and urine employing a modified naphthoresorcinol reagent." (1970). Electronic Theses and Dissertations. 6086.

https://scholar.uwindsor.ca/etd/6086

This online database contains the full-text of PhD dissertations and Masters' theses of University of Windsor students from 1954 forward. These documents are made available for personal study and research purposes only, in accordance with the Canadian Copyright Act and the Creative Commons license-CC BY-NC-ND (Attribution, Non-Commercial, No Derivative Works). Under this license, works must always be attributed to the copyright holder (original author), cannot be used for any commercial purposes, and may not be altered. Any other use would require the permission of the copyright holder. Students may inquire about withdrawing their dissertation and/or thesis from this database. For additional inquiries, please contact the repository administrator via email (scholarship@uwindsor.ca) or by telephone at 519-253-3000ext. 3208. 


\author{
DETERMINATION OF TOTAL AND CONJUGATED \\ GLUCURONIC ACID IN SERUM AND \\ URINE EMPLOYING A MODIFIED \\ NAPHTHORESORCINOL REAGENT
}

BY

ANGELO MAZZUCHIN

Submitted to the Faculty of Graduate studies through the
Department of Chemistry in Partial Fulfillment
of the Requirements for the Degree of
Doctor of Philosophy at the
University of Windsor

windsor, ontario

1970 
UMI Number: DC52654

\section{INFORMATION TO USERS}

The quality of this reproduction is dependent upon the quality of the copy submitted. Broken or indistinct print, colored or poor quality illustrations and photographs, print bleed-through, substandard margins, and improper alignment can adversely affect reproduction.

In the unlikely event that the author did not send a complete manuscript and there are missing pages, these will be noted. Also, if unauthorized copyright material had to be removed, a note will indicate the deletion.

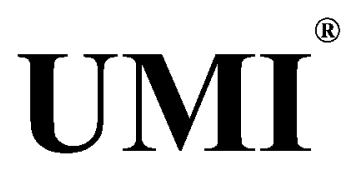

UMI Microform DC52654

Copyright 2008 by ProQuest LLC.

All rights reserved. This microform edition is protected against unauthorized copying under Title 17, United States Code.

ProQuest LLC

789 E. Eisenhower Parkway

PO Box 1346

Ann Arbor, MI 48106-1346 
THIS DISSERTATION HAS BEEN EXAMINED AND APPROVED BY:
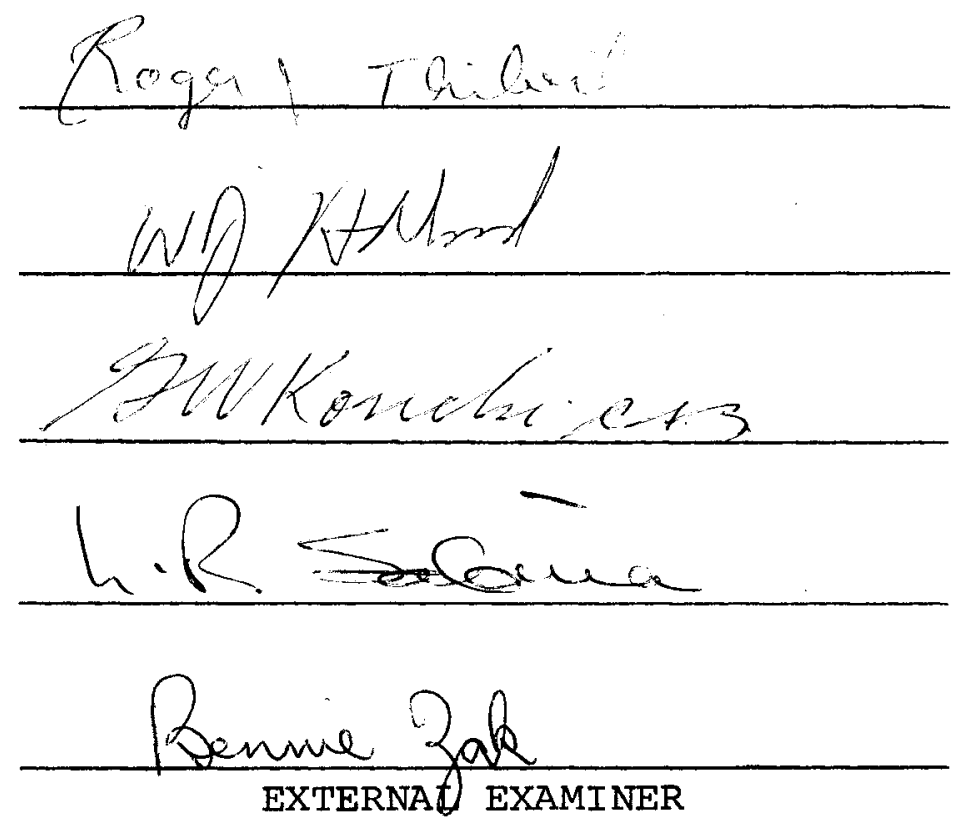

\section{7}


ABSTRACT

A quantitative determination of free, conjugated, and total glucuronic acid in pure and biological systems (serum and urine) has been developed employing a modified naphthoresorcinol procedure. Glucose interference is eliminated selectively with glucose oxidase which permits the determination of glucuronic acid in the presence of high concentrations of glucose. Free glucuronic acid is decomposed with $\mathrm{NaOH}$ to a naphthoresorcinol-negative product in the determination of o-glucuronides. The procedure utilizes a modified naphthoresorcinol reagent and a reduced volume of extracting agent. The method is six to eight times more sensitive than the previous naphthoresorcinol procedures. The reagent is stable for seven days and yields reproducible results. The method of standard addition is employed for the analysis, which results in increased accuracy at low concentrations in the determination of free and conjugated glucuronic acid. The accuracy of the method is $\pm 5 \%$ with a precision of $\pm 0.35 \mu \mathrm{g}$ per $3 \mathrm{ml}$ in the optimum concentration range of 3.5 to $16.6 \mu \mathrm{g}$ per $3 \mathrm{ml}$. The total time required for 
a complete analysis on either serum or urine is four hours.

A titrimetric determination of glucose, galactose, and xylose has been developed employing $\mathrm{N}$-bromosuccinimide. The reactions are performed at room temperature for 15 minutes and the errors are less than $\pm 6 \%$ at the milligram level. 
ACKNOWLEDGEMENTS

Grateful acknowledgement is made to Professor R. J. Thibert, Ph.D., for his many constructive suggestions regarding the design and direction of this research project. I also wish to gratefully acknowledge Dr. R. J. Walton for his assistance in the execution of this project.

I also wish to acknowledge the financial assistance provided by the Ontario Graduate Fellowships. 


\section{DEDICATION}

To Dale, whose love and moral support inspired in me the confidence and patience required throughout graduate school. 
TITLE PAGE • • • • • . . . . • . . . . •

ABSTRACT . . . . . . . . . . . . . . . . .

ACKNOWLEDGEMENTS . . . . . . . . . . . . . . . IV

DEDICATION • . . . . . . . . . . . . . $\mathrm{V}$

TABLE OF CONTENTS . . . . . . . . . . . . . . . . vi

ABBREVIATIONS . . . . . . . . . . . . . . . . ix

LIST OF FIGURES . . . . . . . . . . . . . $\mathrm{x}$

LIST OF TABLES . . . . . . . . . . . . . . $\quad$ xi

Chapter

I INTRODUCTION . . . . . . . . . . . 1

II EXPERIMENTAL . . . . . . . . . 12

A. Modified naphthoresorcinol

procedure - Materials and

Methods . . . . . . . 12

1) Apparatus . . . . . . 12

2) Reagents ........ . . 12

3) Modified Naphthoresorcinol Reagent . . . . . . .

4) Study of variables in the NR Procedure ....... 14

5) Spectral and Stability Study of MNR product . . . 
6) MNR Procedure for Glucuronic Acid . . . . . 16

7) Stability of MNR Reagent. . 17

8) Glucose Interference study 17

9) Gluconic Acid Study . . . 18

10) Determination of Glucuronic Acid in the Presence of Glucose . . . . . . .

11) Determination of Conjugated Glucuronic Acid in the Presence of Free Glucuronic Acid. . . . . . . .

12) Determination of Total and Conjugated Glucuronic Acid in Synthetic Mixtures by Method of Standard Addition . . . . . .

13) Glucuronide study in serum. 23

14) Denaturation Studies . . 23

15) Analysis in Urine ..... 24

B. Titrimetric determination of Glucose, Galactose, and Xylose with $\mathrm{N}$-bromosuccinimide Materials and Methods . . .

1) Reagents . . . . . . 25

2) $\mathrm{pH}$ studies . . . . . . 26

3) Titrimetric Determination of Glucose ....... . 26

4) Titrimetric Determination of Galactose and Xylose . 
viii

Chapter

Page

III RESULTS AND DISCUSSION . . . . .

29

A. Modified Naphthoresorcinol

Procedure . . . . . . . .

29

B. Titrimetric Determination of Glucose, Galactose, and Xylose with $\mathrm{N}$-Bromosuccinimide . . .

SUMMARY AND CONCLUSION . . . . .

78

BIBLIOGRAPHY

80

VITA AUCTORIS • • . . . . . . . . . .

87 


\section{ABBREVIATIONS}

GA

glucuronic acid

MNR modified naphthoresorcinol

NBS N-bromosuccinimide

NR naphthoresorcinol

Spike method of standard addition

P-Gide phenolphthalein momo- $\beta$-glucuronic acid 


\section{LIST OF FIGURES}

Figure

Page

1. Absorption Spectra of Various NR

Products . . . . . . . . . . . .

2. Beer's Law Study of Various NR

Procedures . . . . . . . . .

3. Stability study of MNR Reagent . . . 40

4. Glucose Interference Study with

Glucose Oxidase . . . . . . . . .

5. Flow Diagram outlining Procedure for

a Single Sample . . . . . . . 52

6. Determination of Total and conjugated Glucuronic Acid in Synthetic Mixtures by the Method of Standard Addition . .

7. Loss of P-Gide on Deproteinization .

8. Comparison of Beer's Law Curves Obtained Throughout this study . . . 


\section{LIST OF TABLES}

Table

Page

I Study of Variables in the NR

Procedure .. . . . . . . . . .

II Determination of D-glucuronic Acid and P-Gide in Various Mixtures . . . 48

III Determination of Total and Conjugated Glucuronic Acid in Synthetic Mixtures.

IV Recovery Studies in Serum . . . . .

$\mathrm{V}$ Effect of Protein Concentration on Slopes ...............

VI Determination of Glucuronic Acid and Glucuronide in Serum ........ .

VII Determination of Glucuronic Acid and Glucuronide in Urine . . . . . . 68

VIII pH Range for Maximum Recovery . . . . 75

IX Recovery Studies . . . . . . . . 77 
CHAPTER I

INTRODUCTION

The uronic acids are generally defined as aldose derivatives retaining the original carbon skeleton of the sugar and psuedo-aldehydic group at $\mathrm{c}-1$ and possessing a terminal carboxylic acid group. The three common naturally occurring uronic acids are D-glucuronic acid (I), D-galacturonic acid (II), and D-mannuronic acid (III), all of which are aldohexuronic acids. In aqueous solution and probably in the<smiles>O=C[C@H](O)[C@H](O)[C@H](O)[C@H](O)[C@H](O)C(=O)O</smiles>

I<smiles>O=C[C@H](O)[C@H](O)[C@H](O)[C@H](O)[C@H](O)C(=O)O</smiles>

II<smiles>O=CC(O)C(O)C(O)C(O)C(O)C(=O)O</smiles>

III

crystalline state the predominant species of a hexuronic acid has the cyclic pyranoside structure.

D-glucuronic acid is the most common natural uronic acid and is found principally in the combined form in which the linkage is either of the ether or ester types. 
It is found in polysaccharide form in mucopolysaccharides and mucoproteins of blood and connective tissue (1). Hyaluronic acid (IV), the predominant mucopolysaccharide of connective tissue, contains D-glucuronic acid, D-glucosamine, and acetic acid. D-glucuronic acid is also present in other physiologically important mucopolysaccharides such as; chondroitin sulfates, dermatan sulfate, and heparin (2). In animals and humans, it is a structure
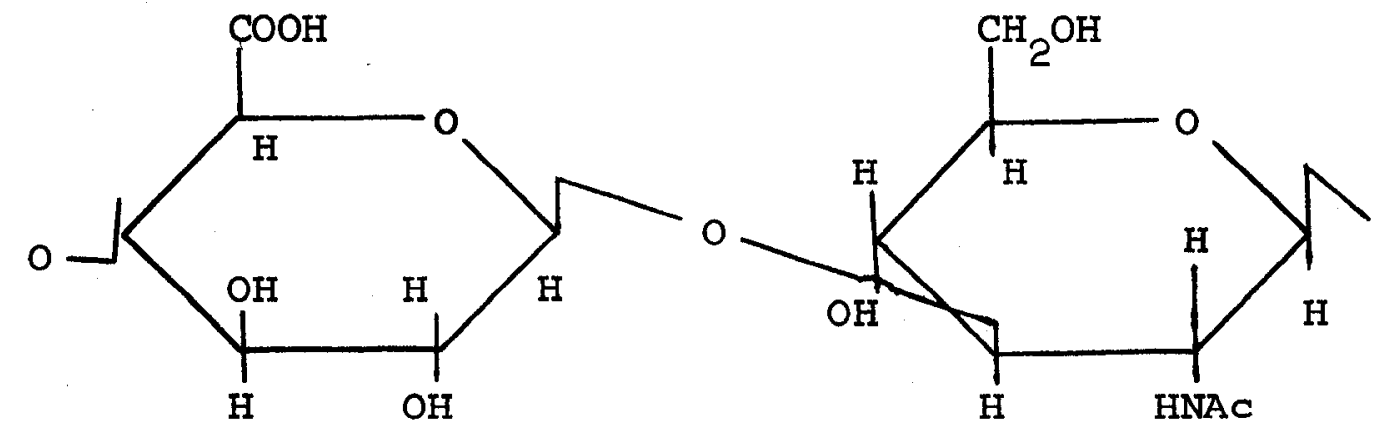

Repeating unit of Hyaluronic Acid (IV)

constituent of essentially all fibrous and connective tissue. The specific role of glucuronic acid as part of these polysaccharide is generally unknown. Considering the above, D-glucuronic acid and D-glucurone have been utilized in the treatment of "collagen diseases" by Peterman, Hoakes, Smith, and Ruggie (3). collagen diseases such as rheumatic fever, 
rheumatoid arthritis, scleroderma, acute lupus erythematosis and atherosclerosis $(4,5)$ are considered as diseases of connective tissue where the metabolism of the mucopolysaccharides have been altered. It would seem therefore that a method capable of determining total and combined glucuronic acid in blood serum would be useful in diagnosis or monitoring of the aforementioned pathological conditions.

Glucuronic acid is also involved in conjugation reactions. Conjugations are generally regarded as detoxification mechanisms, for compounds which undergo these reactions are converted into products which are usually less toxic and more rapidly excreted than their precursors.

The main reactions involving conjugation are those utilizing glucuronic acid, sulfate, glycine, cysteine, methyl, and acetyl groups as the conjugating agent. of these reactions, glucuronic acid conjugation is probably the most important, for it occurs extensively in man (6). The major organs involved in glucuronide biosynthesis are the liver, kidney, and alimentary tract $(7,8)$. of these the liver is considered the major source (9). Thus, clinical investigators have attempted to correlate the 
concentration of glucuronic acid (total and combined) in serum and urine to various liver diseases (10-12). Others have studied the effect of various drugs, hormones, and other diseases on glucuronide biosynthesis in the liver (13-17). However, the interpretations of these results into a general pattern has been hampered by variations in quantitative procedures. The methods for the determination of glucuronic acid seem to have been quite well worked out, but a consideration of the original papers shows that there are as many "normal values" for Dglucuronic acid in biological fluids as there are methods making it quite difficult to interpret which value is really correct.

An accurate, sensitive, and general method for the quantitative determination of glucuronic acid in biological fluids is required. Such a method could be utilized in determining liver damage, monitoring drug therapy, diagnosis of collagen diseases, and provide clinical information leading to the diagnosis of other diseases. However, before outlining our approach to this problem, a brief survey of the available methods seems pertinent at this point. Glucuronic acid has been quantitatively determined 
by many different methods. These methods can be categorized into two general types; classical wet methods and instrumental methods of analysis. Titrimetric (18-21) and manometric methods (22) are representative of the classical determinations, whereas gas chromatography $(23,24)$, polarography $(22,25)$ and spectrophotometry are more modern methods. The most common type of quantitative determination employs spectrophotometry. Various chromogenic reagents have been used, for example: naphthoresorcinol (26-33); carbazole (34-44); anthrone (45-47); resorcinol $(48,49)$; sulphuric acid (50-52); phloroglucinol (53); orcinol (38); hydroxylamine hydrochloride (45-54); phenol (55). An excellent review on the experimental methods for uronic acids have been written by $\mathrm{z}$. Dische (56).

The method most commonly employed for the determination of glucuronic acid in biological fluids is the naphthoresorcinol reaction. It was introduced by Tollens (57) as a qualitative test for determining urinary conjugates of D-glucuronic acid. All modifications (58-62) of the reaction depart from the 
following basic procedures: on boiling an aqueous solution of D-glucuronic acid, naphthoresocinol, and a strong mineral acid, a blue pigment is formed which is extracted into an organic solvent. A colour varying from blue in alcohols to violet-pink in ether results; it is estimated colorimetrically.

The nature of the product of uronic acid and naphthoresorcinol in the Tollens reaction is still in doubt. Guerrero and williams (63) observed that a blue solid, apparently identical with the pigment, was produced by fusing D-glucuronolactone or D-galacturonic acid with naphthoresorcinol at $100^{\circ}-120^{\circ} \mathrm{C}$. Furfural produced a less intensely coloured product when used in place of uronic acids, while (-)-menthyl- $\beta$-D-glucosiduronic acid gave no colour unless oxalic acid was present suggesting that the reducing group of the sugar residue must be free before pigment formation can occur. These workers suggested for the pigments either a diphenylmethane structure (V) or that of a xanthene derivative (VI) derived from dehydration of (V), the carboxyl group of the uronic acid not being involved. This, however, does not satisfactorily explain the specific nature of the reaction; why, for example, it is also given by 2-deoxy-D-galactosid- 
uronic acids (64), but not D-glucosaminuronic acids (65).<smiles>C[C@H](O)/C(=C1\C(O)=CC(=O)c2ccccc21)c1c(O)cc(O)c2ccccc12</smiles>

(v)<smiles>O=C(O)C(C(=O)O)c1c2c3ccccc3c(=O)cc-2oc2cc(O)c3ccccc3c12</smiles>

(VI)

Momose et al. $(66,67)$ methylated with diazomethane the same fusion product of D-glucuronic acid and naphthoresorcinol and found a complex mixture of dyes to be present, containing four chromatographically separable constituents of differing melting points. The infrared spectra suggested the presence of lactones, and the two main derivatives were identified as a pyrone derivative (VII), and VIII) obtained by partial degradation of the uronic acids. Both these structures involve dehydration of the uronic acid molecule. Other structures have been proposed by Nozaki (68). 
<smiles></smiles>

(VII)<smiles>O=C1C[CH]C(c2c3c4ccccc4c(=O)cc-3oc3cc(O)c4ccccc4c23)O1</smiles>

As a quantitative method for the determination of uronic acid, the naphthoresorcinol reaction has been used very widely, and an accuracy of about $\pm 5 \%$ can usually be obtained with pure solutions containing 10-100 $\mu g$ of uronic acid per milliter. Its main disadvantages have been the wide variability of the sensitivity, and the background colour varying in intensity with different specimens of naphthoresoricinol or even with different solutions made from the same sample; consequently, repeated controls with standard D-glucuronic acid solutions are essential.

To explain these variations, it has often been suggested that the chromogenic agent involved is not naphthoresorcinol but an oxidation product derived from it, and artificially aged solutions have been 
recommended as being more stable than fresh preparations. Thus Maughan et al. (58) employed solutions previously kept at $38^{\circ} \mathrm{C}$ for 24 hours, then stored at $3^{\circ}-5^{\circ} \mathrm{C}$ in the dark; bubbling oxygen through the naphthoresorcinol solution before use has also been suggested (69). Freshly prepared aqueous solutions of naphthoresorcinol are pale yellow, but darken to a reddish colour within a few days, especially in the presence of air, and insoluble material is gradually deposited. Aged solutions give a pink colour on extraction with most organic solvents and appreciably higher blank values. The coloured pigment may be extracted with diethyl ether (58), amyl alcohol (60), toluene (62), or $\beta, \beta$-dichloroethyl ether (31), the wavelength at which the colorimetric measurement is performed being determined by the solvent employed; thus extraction with amyl alcohol yields a deep blue solution, and with ether, chloroform, toluene, or ethyl acetate, violet colours.

All the common hexuronic acids, and some monosubstituted uronic acids, give the naphthoresorcinol reactions, D-glucuronolactone being quantitatively equivalent, on a molar basis, to D-glucuronic acid. D-glucosiduronic acids generally react as free D- 
glucuronic acid, and the method has been adapted to the determination of total and conjugated D-glucuronic acid in mixtures (62). This particular modification of the naphthoresorcinol reaction described by $F$ ishman has been the preferred method in many biochemical studies (70-74). This method, however, is inaccurate in the presence of high concentrations of glucose since the naphthoresorcinol reaction is actually a group reaction for hydroxy-carbonylcarboxylic acid, and simple sugars may interfere. The one most serious source of interference in biological fluids is glucose $(31,59,75,76)$. Although many investigators (77-80) have reported success in removing glucose interference, the procedures have been found to be too time consuming and the results were unsatisfactory (31, $60)$.

The greatest limiting factors in acquiring an accurate method for the determination of total and conjugated glucuronic acid are: the presence of interfering substances $(31,59,60)$; the stability of the naphthoresorcinol reagent $(33,58)$; poor sensitivity at low levels of glucuronic acid; and the inability to selectively eliminate glucose interference and free glucuronic acid. The present study is concerned with the following: 
selectively eliminating glucose interference employing glucose oxidose; decomposing free glucuronic acid with $\mathrm{NaOH}$ in the determination of glucuronides; studying the effect of varying certain parameters in the naphthoresorcinol procedure with a view to obtaining greater sensitivity, stability, accuracy, and reproducibility; and to utilize this procedure for the determination of total and conjugated glucuronic acid in serum and urine. 
CHAPTER II

EXPERIMENTAL

\section{A. Modified Naphthoresorcinol Procedure}

Materials and Methods

\section{1) Apparatus}

Spectral and absorbance measurements were made with a Beckman DB spectrophotometer employing a Sargent SRL recorder. Stability studies were performed on a Beckman DU monochromator with a Gilford Model 2000 Multiple Sample Recorder and a Haake thermostated circulating water pump $\left(25 \pm 0.5^{\circ} \mathrm{C}\right)$ with matched silica cells of $1-\mathrm{cm}$ path length. Constant temperature water baths were set at $37 \pm 1^{\circ} \mathrm{C}$ and $100^{\circ} \pm 1^{\circ} \mathrm{C}$. Glassstoppered test tubes ( $25 \times 200 \mathrm{~mm}$ ) and centrifuge tubes $(16 \times 115 \mathrm{~mm})$ were utilized throughout this study. A Vortex-Genie mixer was employed during deproteinization. An International Clinical Centrifuge Model CL was employed for centrifugation and $\mathrm{pH}$ measurements were performed on a Fisher Accumet pH Meter Model 19.

2) Reagents

D-glucuronic acid (Grade 1) and phenolphthalein mono- $\beta-$ glucuronic acid were obtained from Sigma Chemical 12 
Company, st. Louis, U.S.A. All solutions were made up in deionized, distilled water. Purified naphthoresorcinol and anhydrous D-glucose (A.C.S. certified) were obtained from Fisher Scientific Company, Canada. Glucose Oxidase Type V (1,000 E.U. per ml) was purchased from Sigma Chemical company. One unit of this enzyme will oxidize 1 umole of glucose to gluconic acid and $\mathrm{H}_{2} \mathrm{O}_{2}$ per minute at $\mathrm{pH} 5.1$ at $35^{\circ} \mathrm{C}$. The following reagents employed were of analytical grade: concentrated hydrochloric acid and sulphuric acid; redistilled ethyl acetate; redistilled toluene. Analytical grade reagents were utilized in preparing the following solutions: aqueous $2.0 \mathrm{~N}$ sodium hydroxide; aqueous $10 \%(\mathrm{w} / \mathrm{v})$ phosphoric acid; sodium tungstate $5 \%(\mathrm{w} / \mathrm{v})$; n-octanol.

3) Modified Naphthoresorcinol Reagent (MNR)

A variation of the reagent as utilized by Nir (33) was prepared. Naphthoresorcinol (NR), $400 \mathrm{mg}$, was dissolved in about $80 \mathrm{ml}$ of deionized, distilled water and $0.5 \mathrm{~N}$ sodium hydroxide was added dropwise to adjust the $\mathrm{pH}$ between 8-8.5. After allowing the solution to stand for $15 \mathrm{~min}, 10 \%(\mathrm{w} / \mathrm{v})$ phosphoric acid was added from a pasteur pipet until a $\mathrm{pH} 2-2.5$ was obtained. The solution should turn light yeilow. The solution 
was continually stirred by means of a magnetic stirrer. Sodium bisulfite ( $200 \mathrm{mg}$ ) was added and the volume was adjusted to $100 \mathrm{ml}$ with deionized water. This solution was filtered twice, refrigerated $\left(0-5^{\circ} \mathrm{c}\right)$, and protected from light until use (100-ml volumetric flask was wrapped with aluminum foil).

4) Study of Variables in the NR procedure The concentration of glucuronic acid was maintained at $50 \mu \mathrm{g}$ per $2.0 \mathrm{ml}$ of test solution throughout this study. The variables studied were as follows: hydrochloric acid volume in reaction; concentration of naphthoresorcinol; sulphuric acid media; toluene as an extracting agent; decreased volume of ethyl acetate as the extracting agent. The procedure was basically that of $\operatorname{Nir}(33)$. The sugar solution (2.0 ml) was pipetted into the glass-stoppered test tubes to which $2.0 \mathrm{ml}$ of the naphthoresorcinol reagent under study were added. Three preparations of NR reagent were studied: aqueous $0.2 \mathrm{mg} \% \mathrm{NR}$; $0.2 \mathrm{mg} \% \mathrm{NR}$ (Nir reagent); and $0.4 \mathrm{mg} \% \mathrm{MNR}$. Various acids and volumes of acid are then added to this mixture. Blanks were prepared by substituting $2.0 \mathrm{ml}$ of water for the glucuronic acid. The tubes were then stoppered and the solutions therein mixed (the tubes were 
covered with a damp cloth to prevent the stoppers from jumping out during the heat treatment). The samples were then placed in a boiling water bath $\left(100 \pm 1^{\circ} \mathrm{C}\right)$ for 30 minutes. After the heating step, the samples were immersed in an ice bath for 10 min. Various volumes of extracting agents were then added by burette and the samples were agitated for 30 seconds. The organic layer in each of the tubes were removed by pasteur pipets and transferred directly to a cuvette. The absorbance was read at the appropriate wavelength. The two extracting agents employed were toluene and ethyl acetate. The absorbances were read at $565 \mathrm{~nm}$ and $580 \mathrm{~nm}$ for toluene and ethyl acetate, respectively.

The effect of time of heating on the reaction mixtures was studied. The reaction mixtures consisted of $2.0 \mathrm{ml}$ of test solution ( $10 \mu \mathrm{g} / \mathrm{ml} \mathrm{glucuronic}$ acid), 2.0 ml MNR and $2.0 \mathrm{ml}$ concentrated hydrochloric acid. Three experiments were performed on these mixtures, as described earlier, except for periods of heating (30, 60, and 90 min periods at $100^{\circ} \mathrm{C}$ ). After cooling, the samples were extracted with $3.0 \mathrm{ml}$ ethyl acetate. The absorbance in the organic layer was read at $580 \mathrm{~nm}$. All absorbance measurements reported are the average of duplicate 
analysis.

5) Spectral and Stability Study of MNR Product The spectrum and the stability of the reaction product extracted into $3.0 \mathrm{ml}$ redistilled ethyl acetate from a reaction mixture consisting of $2.0 \mathrm{ml}$ glucuronic acid solution $(50 \mu \mathrm{g} / 2 \mathrm{ml}), 2.0 \mathrm{ml}$ MNR reagent, and 2.0 ml of concentrated hydrochloric acid were examined. The basic experimental procedures with regards to handling and cooling times were the same as described in the previous section. The samples were heated for $90 \mathrm{~min}$ in a boiling water bath.

\section{6) MNR Procedure for Glucuronic Acid}

The following solutions were pipetted into glass-stoppered test tubes: $3.0 \mathrm{ml}$ glucuronic acid solution; $2.0 \mathrm{ml}$ concentrated $\mathrm{HCl} ; 2.0 \mathrm{ml}$ of $0.4 \mathrm{mg} \%$. MNR. Blanks were prepared with $3.0 \mathrm{ml} \mathrm{H}_{2} \mathrm{O}$ instead of glucuronic acid solution. The concentration range studied was $\mathrm{O}-$ $20 \mu \mathrm{g}$ per $3.0 \mathrm{ml}$ of glucuronic acid. The test tubes were then stoppered and shaken. After having covered the test tubes with a damp cloth, they were then placed in a boiling water bath for $30 \mathrm{~min}$. This study was repeated except that a heating period of $90 \mathrm{~min}$ was used. The samples were then immersed in an ice bath for $10 \mathrm{~min}$ 
and exactly $3.0 \mathrm{ml}$ of redistilled ethyl acetate were added from a burette and the samples shaken for 30 seconds. The ethyl acetate layer was then transferred to a cuvette by means of a pasteur pipet and the absorbance was read at $564 \mathrm{~nm}$.

A comparative study of the sensitivity of the present method with that of Fishman $(62,76)$ and Nir (33) was carried out.

\section{7) Stability of the MNR Reagent} The stability of the MNR reagent was monitored by performing regularily the MNR procedure $(90 \mathrm{~min}$ heating period) over a two week period utilizing a single preparation of the reagent. The samples, in duplicate, consisted of a blank and $10 \mu \mathrm{g}$ per 3.0 milliliters of glucuronic acid. The absorbance versus age of reagent was plotted.

8) Glucose Interference Study Two-milliliter samples containing different concentrations of glucose were incubated with $0.1 \mathrm{ml}$ glucose oxidase (Type $\mathrm{V}$ ) and $1.9 \mathrm{ml}$ of a $0.1 \mathrm{M}$ acetate buffer $\mathrm{pH} 5.6$ at $37^{\circ} \mathrm{C}$ for $90 \mathrm{~min}$. The samples were aerated throughout the incubation period. The samples were then deproteinized by the method of Bonsenes and 
Taussky (81). Two milliliters of a $5 \%(\mathrm{w} / \mathrm{v})$ sodium tungstate solution were pipetted into the samples contained in the glass-stoppered test tubes. Two milliliters of $2 / 3 \mathrm{~N} \mathrm{H}_{2} \mathrm{SO}_{4}$ were then added dropwise from a burette as the samples were being agitated by a Vortex mixer. After allowing the samples to stand for $10 \mathrm{~min}$, they were transferred to centrifuge tubes and centrifuged in a clinical centrifuge for $5 \mathrm{~min}$. Three milliliters of the supernatant were then utilized as the samples for the MNR procedure.

A second study was conducted in which 1.0 -ml samples diluted to $2.0 \mathrm{ml}$ with deionized, distilled water were incubated for $45 \mathrm{~min}$ and $1.5-\mathrm{ml}$ aliquots were taken after deproteinization. These aliquots were diluted to $3.0 \mathrm{ml}$ and utilized for the MNR reaction. Blanks in both systems contained the appropriate volume of water instead of glucose solution. The concentration range of glucose studied was $0-600 \mathrm{mg} \%$. The absorbance was read at $564 \mathrm{~nm}$.

\section{9) Gluconic Acid Study}

The MNR procedure was performed on samples containing varying amounts of gluconic acid. The samples were treated in the same manner as described in the glucose 
interference study (1.0-ml samples) except, no enzyme or incubation period was required. The concentration range of gluconic acid studied was $0-600 \mathrm{mg} \%$. The absorbance was read at $564 \mathrm{~nm}$.

10) Determination of Glucuronic Acid in the Presence of Glucose

Glucuronic acid concentration was determined in the presence of $3 \mathrm{mg}$ per $\mathrm{ml}$ glucose following the exact procedure with respect to incubation time $(45 \mathrm{~min})$ and deproteinization as described in the previous section. One-milliliter samples were taken and $1.5-\mathrm{ml}$ aliquots (of the deproteinized samples) were utilized for the MNR reaction. Blanks contained glucose and all analyses of samples were carried out in duplicate. The samples were heated for $30 \mathrm{~min}$ in the boiling water bath and the concentration of glucuronic acid was determined from a standard curve. Standards run simultaneously with the blanks and samples contained no glucose.

11) Determination of Conjugated Glucuronic Acid in the Presence of Free Glucuronic Acid One milliliter of $1.0 \mathrm{~N} \mathrm{NaOH}$ was added to 2.0 ml samples which contained a mixture of D-glucuronic acid and phenolphthalein mono-k-glucuronide (P-Gide). A 
spectral analysis was performed on these samples. The glucuronic acid concentration was constant at $10 \mu \mathrm{g}$ per $\mathrm{ml}$ and the concentration of $\mathrm{P}-\mathrm{Gide}$ varied from $7.3 \mu \mathrm{g}-$ $21.9 \mu \mathrm{g}$ per $2.0 \mathrm{ml}$. The samples were heated for $20 \mathrm{~min}$ at $100^{\circ} \mathrm{C}$ and allowed to cool in a cold water bath. The samples were then subjected to the MNR procedure $(90 \mathrm{~min}$ heating) for the determination P-Gide. The concentration of P-Gide was determined from a standard curve of P-Gide.

12) Determination of Total and Conjugated Glucuronic Acid in Synthetic Mixtures by the Method of

\section{Standard Addition}

The synthetic samples contained D-glucose, D-glucuronic acid, and P-Gide. The concentration of glucose was constant in all samples ( $3 \mathrm{mg}$ per $\mathrm{ml}$ ) and the volume of sample taken was $1.0 \mathrm{ml}$. The concentration of glucuronic acid and P-Gide in the samples varied from $5 \mu \mathrm{g}$ to $20 \mu \mathrm{g}$ and $5.98 \mu \mathrm{g}$ to $11.96 \mu \mathrm{g}$, respectively. The ratios of glucuronic acid to P-Gide studied were $1: 1$ and 2:1. Blanks contained $3 \mathrm{mg}$ per $\mathrm{ml}$ of glucose. A single sample was treated as outlined in Fig. 5. One-milliliter samples were diluted to $2.0 \mathrm{ml}$ and were incubated for $45 \mathrm{~min}$ with continuous aeration at $37^{\circ} \mathrm{C}$. The incubation mixture consisted of $2.0 \mathrm{ml}$ of sample, 
$0.1 \mathrm{ml}$ of glucost uxidase and $1.9 \mathrm{ml}$ of $0.1 \mathrm{M}$ acetate buffer, pH 5.6. The samples were then deproteinized and centrifuged as described earlier. After deproteinization the total volume of the reaction mixture is $8.0 \mathrm{ml}$. Four 1.5-ml aliquots of the supernatant from the sample were pipetted into four glass-stoppered test tubes. One set of duplicates was utilized for the determination of total glucuronic acid and the other set for conjugated glucuronic acid.

In order to determine the endogenous concentration of glucuronic acid of a particular sample, four replicate samples were treated as described above. These four replicates result in sixteen aliquots or eight sets of duplicates after deproteinization. Four sets were utilized for the determination of conjugated glucuronic acid and the remaining four for the determination of total glucuronic acid. Free glucuronic acid was determined by difference between total and conjugated glucuronic acid.

In the determination of endogenous total glucuronic acid three sets were spiked with varying concentrations of P-Gide. The concentration of spike utilized were $5.98 \mu \mathrm{g}, 8.98 \mu \mathrm{g}$, and $11.96 \mu \mathrm{g}$. (Therefore, the result 
of the above treatment was four sets of duplicates of which three were spiked and one unspiked.) All samples were then diluted to $3.0 \mathrm{ml}$ with water and were subjected to the MNR procedure. The absorbance readings of the spiked and unspiked samples were plotted against known concentration of P-Gide spike, and the endogenous total glucuronic acid was determined by extrapolating the straight line back to the $\mathrm{x}$-axis. This straight line was then utilized as the standard curve for the determination of endogenous total glucuronic acid for other synthetic samples - these samples need not be spiked.

In the determination of conjugated glucuronic acid, the remaining four sets were spiked as described for total glucuronic acid and $0.5 \mathrm{ml}$ of $2.0 \mathrm{~N} \mathrm{NaOH}$ was added and the samples diluted to $3.0 \mathrm{ml}$ with water. The samples were stoppered and covered with a damp towel and placed in a boiling water bath for $20 \mathrm{~min}$. After cooling to room temperature in a cold water bath, the samples were subjected to the MNR procedure and the same calculations were performed as described for total glucuronic acid. To determine the amount of total or conjugated glucuronic acid in the original 1.0-ml sample, the amount determined 
from the curve is multiplied by the dilution factor $8 / 1.5$ or 5.33

\section{3) Glucuronide Study in Serum}

To determine any loss of P-Gide during deproteinization $1.0,0.5,0.25 \mathrm{ml}$ samples of pooled sera were taken and spiked before and after deproteinization. The glucose concentration of the serum was determined by the alkaline ferricyanide method on the AutoAnalyzer (83) and was found to vary between $115-117 \mathrm{mg} \%$. The blanks contained $1 \mathrm{mg}$ per $\mathrm{ml}$ of glucose. The total volume of spike and sample was maintained at $2.0 \mathrm{ml}$ before deproteinization and $3.0 \mathrm{ml}$ after deproteinization. The samples were treated as described for the synthetic samples except that to the incubation mixture $0.02 \mathrm{ml}$ of n-octanol was added to prevent foaming during aeration. Reproducibility studies were done on sera samples for both total and conjugated glucuronic acid.

\section{4) Denaturation Studies}

In an attempt to increase the recovery of glucuronic acid in serum protein denaturing agents were utilized. The denaturing agents employed were urea, Triton $\mathrm{x}-100$, and sodium deoxycholic acid which were $8 \mathrm{M}$, $0.1 \%(\mathrm{v} / \mathrm{v})$, and $.005 \mathrm{M}$, respectively. Samples were 
treated with urea before deproteinization and were made $8 \mathrm{M}$ in urea concentration. The MNR procedure described for the glucuronide study, above, was then carried out. Serum samples $(0.5 \mathrm{ml})$ were treated as described above except that $2.0 \mathrm{ml}$ of the other denaturing agent was added to the protein precipitates and the resulting solutions were agitated on the Vortex mixer for two min and allowed to stand at room temperature for $15 \mathrm{~min}$. The samples were then centrifuged and the supernatants were transferred by pasteur pipet to the corresponding supernatants from the initial deproteinizations. Aliquots $(1.5 \mathrm{ml}$ ) were utilized and treated as described in the glucuronide study. The per cent recovery was calculated by utilizing the curve obtained from spiking after deproteinization as the standard curve.

\section{5) Analysis in Urine} Three 24-hour urine specimens were collected from adults and stored under toluene at $0-5^{\circ} \mathrm{C}$. Fivemiliiliter urine samples were heated for $5 \mathrm{~min}$ at $100^{\circ} \mathrm{C}$. When precipitates appeared, they were removed by centrifugation. One-milliliter of urine was diluted to $2.0 \mathrm{ml}$ with deionized water and incubated in the same manner as the synthetic samples. The blanks consisted of $1 \mathrm{mg}$ per 
ml glucose and water. The total incubation mixture was then diluted to $100 \mathrm{ml}$ with deionized water in a 100-ml volumetric flask. Aliquots $(1.5 \mathrm{ml})$ were then utilized for the determination of total and conjugated glucuronic acid as described for the synthetic mixtures. Deproteinization was not required. Reproducibility studies were done on all urine samples and the results obtained for all the determinations were compared to one another. Results reported for each sample are the average of five determinations.

B. Titrimetric Determination of Glucose, Galactose, and Xylose with N-Bromosuccinimide

Materials and Methods

1) Reagents $\mathrm{N}-$ Bromosuccinimide (NBS), approximately $0.05 \mathrm{~N}$ (2.22 grams per $500 \mathrm{ml}$ ), was prepared fresh daily. Anhydrous preparation of glucose, galactose, and xylose were utilized. $\mathrm{NaOH}$ and $\mathrm{KI}$ were of analytical grade. Standard solutions of sodium thiosulfate, approximately $0.01 \mathrm{~N}$, were prepared and standardized in the usual manner

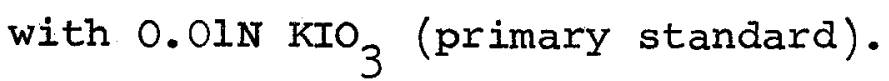

All titrations were performed with a pre-calibrated 
50-ml burette and 250-ml conical flasks with stoppers were employed as the reaction vessels. $\mathrm{pH}$ measurements were performed on a Fisher Accumet pH Meter, Model 19.

\section{2) $\mathrm{pH}$ Studies}

The reaction procedures were performed as described in section 3B for all three sugars with respect to time and volumes of reagents, except 100-ml beakers were utilized and various normalities of $\mathrm{NaOH}$ were added in order to study the $\mathrm{pH}$ range from 4 to 12 . The concentration of sugars was maintained constant throughout this study ( $5 \mathrm{mg}$ per $\mathrm{ml}$ ). $\mathrm{pH}$ measurements were made before and after the $15 \mathrm{~min}$ reaction time. The per cent recovery was calculated as in section 3B, except for xylose whose equivalent weight is 75.07 .

\section{3) Titrimetric Determination of Glucose}

A $1.0-m l$ aliquot of the test solution was transfered to $250-\mathrm{ml}$ conical flasks to which $10.0 \mathrm{ml}$ of $0.05 \mathrm{~N}$ NBS was added. In the case of low concentrations (1 $\mathrm{mg}$ per $\mathrm{ml}), 5.0-\mathrm{ml}$ aliquots of the test solution were employed. Blanks contained the appropriate volume of water instead of sugar solution. The solutions were made alkaline with $2.0 \mathrm{ml}$ of $0.2 \mathrm{~N} \mathrm{NaOH}$. The flasks were stoppered, shaken, and allowed to stand for $15 \mathrm{~min}$ at 
room temperature (in the dark). The solutions were then acidified with $10 \mathrm{ml}$ of $1 \mathrm{~N} \mathrm{HCl}$ and approximately 2 grams of potassium iodide were added. The flasks were again stoppered and shaken. The liberated iodine was titrated with the standard sodium thiosulfate solution using starch as an indicator. The amount of glucose was calculated applying the following relationship:

$$
\mathrm{mg} \text { glucose }=\mathrm{Eq} \cdot \text { Wt. } \mathrm{x} \mathrm{N}_{\mathrm{Na}_{2} \mathrm{~S}_{2} \mathrm{O}_{3}}\left(\mathrm{~V}_{\mathrm{T}_{\mathrm{Blank}}}-\mathrm{V}_{\mathrm{T}_{\text {Sample }}}\right)
$$

where; Eq. Wt. = equivalent weight of the particular

$$
\begin{aligned}
& \text { sugar } \\
& \mathrm{N}_{\mathrm{Na}_{2} \mathrm{~S}_{2} \mathrm{O}_{3}=} \text { Normality of sodium thiosulfate } \\
& \mathrm{V}_{\mathrm{T}_{\mathrm{Blank}}=} \text { Volume of sodium thiosulfate required } \\
& \text { to titrate blank } \\
& \mathrm{V}_{\mathrm{T}} \text { volume of sodium thiosulfate required } \\
& \text { to titrate sample. }
\end{aligned}
$$

The recoveries reported are the average of five determinations.
4) Titrimetric Determination of Galactose and xylose The procedure for the determination of galactose and xylose is different with regards to volume and normality of $\mathrm{NaOH}$ added. For galactose $3.0 \mathrm{ml}$ of $0.2 \mathrm{~N} \mathrm{NaOH}$ and for xylose $2.0 \mathrm{ml}$ of $0.5 \mathrm{~N} \mathrm{NaOH}$ were utilized. The reaction 
time for both sugars was maintained at $15 \mathrm{~min}$. 


\section{RESULTS AND DISCUSSION}

\section{A. Modified Naphthoresorcinol procedure}

The results of the study of the various parameters affecting the naphthoresorcinol (NR) procedure are reported in Table 1. Experiments 1 - 3 illustrate the effect of increasing the concentration of the NR reagent. The results indicate an increase in sensitivity with increasing concentrations of NR. This agrees with the results of Mosher (31). These experiments also indicate that the modified NR reagent is more sensitive than Nir's reagent (33) by a factor of about 1.3. The results of experiments $3-5$ illustrate that when the volume of concentrated hydrochloric acid is increased, the sensitivity reaches a maximum at $4.0 \mathrm{ml}$ and then decreases. This decrease in sensitivity most probably results from acid hydrolysis of some of the ethyl acetate during the extraction, thereby preventing the complete extraction of the NR pigment formed. The substitution of concentrated sulfuric acid in the NR procedure resulted in a turbid ethyl acetate layer and therefore was not utilized as the acid media. Toluene was found 29 
to be inferior to ethyl acetate as an extracting agent due to the turbidity of the organic phase.

Table 1 (experiments 8 - 11) demonstrates the effect of increasing the volume of the extracting agent. As one would expect, an increase in volume results in a decrease in absorbance or sensitivity. The volume of ethyl acetate which resulted in the greatest sensitivity was $3.0 \mathrm{ml}$. An attempt to increase the sensitivity, even further, by increasing the volume of hydrochloric acid resulted in a complete loss of the ethyl acetate layer.

Increasing the time of heating in the boiling water both from 30 to $90 \mathrm{~min}$ also causes an increased absorbance which is in agreement with previously reported data (30, 31,62). Therefore, the conditions for maximum absorbance or sensitivity based on the above observations are: 2.0 $\mathrm{ml}$ of $0.4 \mathrm{mg} \%$ of MNR; $2.0 \mathrm{ml}$ concentrated hydrochloric acid; $90 \mathrm{~min}$ heating period; $3.0 \mathrm{ml}$ redistilled ethyl acetate as the extracting agent. 
TABLE I

Study of variables in NR procedure

\begin{tabular}{|c|c|c|c|c|}
\hline $\begin{array}{l}\text { Expt. } \\
\text { No. }\end{array}$ & $\begin{array}{c}\text { Concentration } \\
\text { NR mg } \%\end{array}$ & $\begin{array}{l}\text { Volume of } \\
\text { acid }(\mathrm{ml})_{\mathrm{d}}\end{array}$ & $\begin{array}{l}\text { Volume of } \\
\text { extracting agent } \\
(\mathrm{ml})_{\mathrm{e}}\end{array}$ & Absorbance \\
\hline 1 & $0.2^{a}$ & 2.0 & 10.0 & 0.175 \\
\hline 2 & $0.2^{b}$ & 2.0 & 10.0 & 0.235 \\
\hline 3 & $0.4^{c}$ & 2.0 & 10.0 & 0.307 \\
\hline 4 & 0.4 & 4.0 & 10.0 & 0.371 \\
\hline 5 & 0.4 & 6.0 & 10.0 & unstable \\
\hline 6 & 0.4 & $2.0\left(\mathrm{H}_{2} \mathrm{SO}_{4}\right)$ & 10.0 & turbid \\
\hline 7 & 0.2 & 2.0 & 10.0 (toluene) & turbid \\
\hline 8 & 0.4 & 2.0 & 3.0 & 1.159 \\
\hline 9 & 0.4 & 2.0 & 4.0 & 0.814 \\
\hline 10 & 0.4 & 2.0 & 5.0 & 0.623 \\
\hline 11 & 0.4 & 2.0 & 6.0 & 0.505 \\
\hline
\end{tabular}

a aqueous $N R$

b NR reagent made up according to Nir (33)

C MNR reagent

d The acid utilized in this study was concentrated hydrochloric acid where mentioned in parenthesis.

e Ethyl acetate was employed as the extracting agent except where mentioned in parenthesis.

f The results reported are the average of duplicate analysis. 
The above conditions were studied with respect to absorption maxima and stability of the NR pigment finally extracted with $3.0 \mathrm{ml}$ redistilled ethyl acetate. The absorption maximum for glucuronic acid under the above conditions is at $564 \mathrm{~nm}$ (Fig. 1). The normal blank versus ethyl acetate has an absorption maximum at $510 \mathrm{~nm}$. The stability of both sample and blank was studied by monitoring the change of absorbance with time. The sample and blank were both stable for the length of study ( 1 hour).

The MNR procedure obeys Beer's law in pure solutions as illustrated by the linear relationship in Fig. 2 (curve 1). This linear relationship is also true for the MNR procedure when a heating period of $30 \mathrm{~min}$ is employed. Figure 2 (curve 3, 4) illustrate the Beer's law relationships for the methods of Fishman (76) and Nir (33). Curve 5 represents the data reported by Nir (33). The results obtained in this laboratory employing Nir's method are lower than those reported by Nir. The molar absorptivity, therefore, was calculated from the data reported by Nir. We could make no such comparison with Fishman's method $(61,62$, 76), due to the lack of data required to calculate 
the molar absorptivity. The molar absorptivity was calculated from the data (curve 3 ) obtained using the method of Fishman in this laboratory. The molar absorptivity (liter mole $\mathrm{cm}^{-1}$ ) of the MNR procedure for $90 \mathrm{~min}$ and $30 \mathrm{~min}$ heating periods are $30.1 \times 10^{3}$ and $16.5 \times 10^{3}$, respectively. The molar absorptivities for Nir's and Fishman's methods are $3.8 \times 10^{3}$ and $5.0 \times 10^{3}$, respectively. This demonstrates that the present method is six times more sensitive than Fishman's method and eight times more sensitive than that of Nir. The optimum concentration ranges as calculated by the Ringbom method (83) for the MNR procedure at $90 \mathrm{~min}$ and $30 \mathrm{~min}$ heating are 3.5 to $16 \mu \mathrm{g}$ per $3.0 \mathrm{ml}$ and 5 to $25 \mu \mathrm{g}$ per $3.0 \mathrm{~m} 1$, respectively (the concentration range for the MNR at $30 \mathrm{~min}$ heating was calculated from curve 2 (Fig. 2) extrapolated to $30 \mu \mathrm{g}$ ). The results of a typical calibration curve indicate standard errors of estimate to be $\pm 0.0150 . \mathrm{D}$. unics and $\pm 0.5 \mu \mathrm{g}$ per $3.0 \mathrm{ml}$. The MNR procedure involves errors in the optimum concentration range that are less than $\pm 5 \%$. 


\section{Legend to Figure 1}

Fig. 1 Absorption spectra of various NR products:

Curve $1,14.6 \mu \mathrm{g}$ per $\mathrm{ml}$ of $\mathrm{P}-\mathrm{Gide}$ reacted with

$\mathrm{NaOH}$ read against blank containing $\mathrm{NaOH}$; Curve 2,

14. $0 \mu$ per $\mathrm{ml}$ glucuronic acid read against normal

blank; Curve 3, Blank containing $\mathrm{NaOH}$ read against

redistilled ethyl acetate; curve 4, normal NR

blank read against redistilled ethyl acetate. 


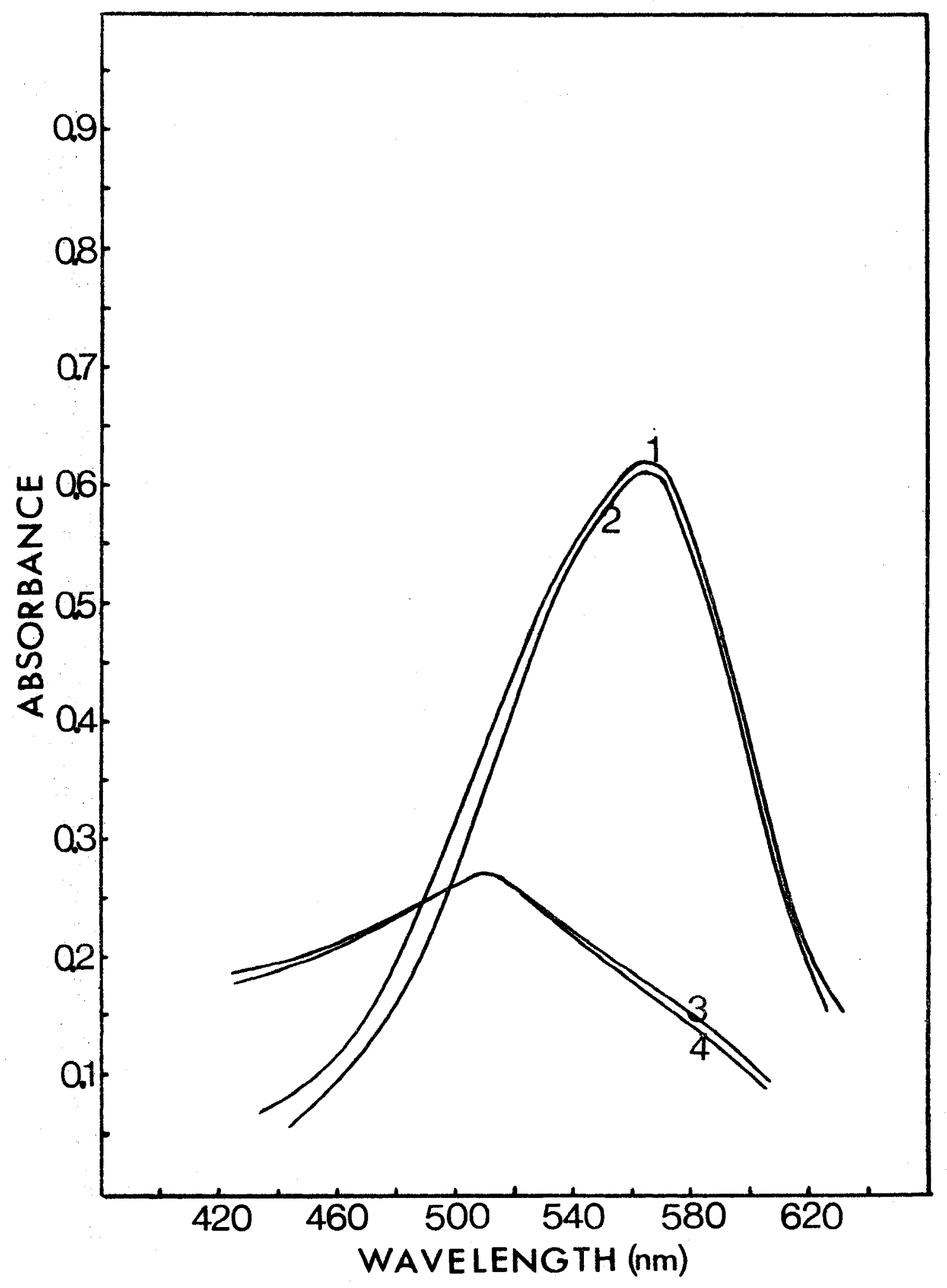


Legend of Figure 2

Fig. 2 Beer's Law study of various NR procedures. Each curve represents the following: Curve 1, MNR procedure, $90 \mathrm{~min}$ heating, $\mu \mathrm{g}$ per $3.0 \mathrm{ml}, 564$ $\mathrm{nm}$; Curve 2, MNR procedure, $30 \mathrm{~min}$ heating, $\mu \mathrm{g}$ per $3.0 \mathrm{ml}, 564 \mathrm{~nm}$; Curve 3, Fishman method (44); Curve 4, Nir method (33), $\mu \mathrm{g}$ per $2.0 \mathrm{ml}, 580$ nm; Curve 5, published data of Nir (33). 


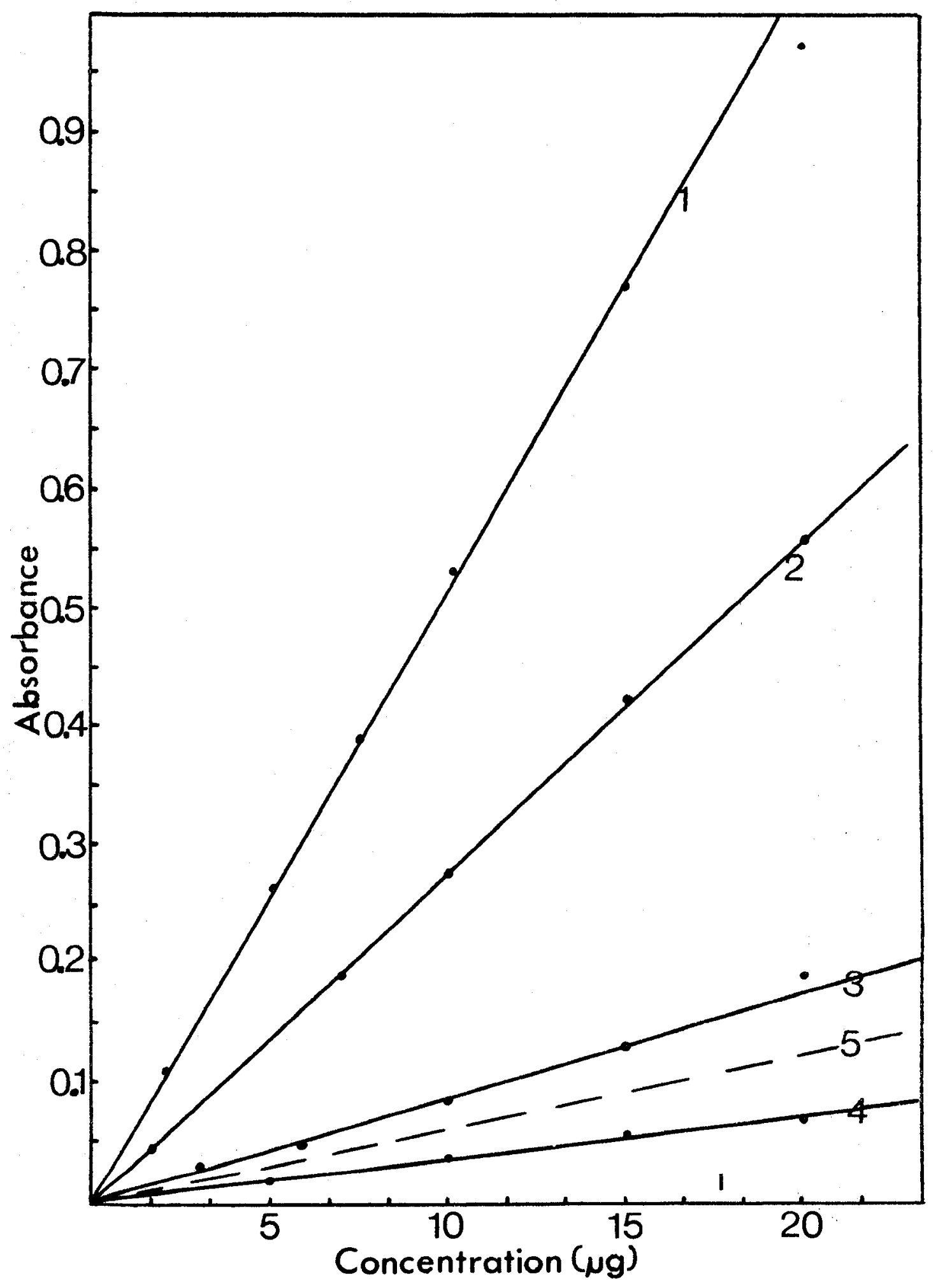


The results of the stability study are illustrated in Figure 3. Curve 1 indicates that the colour produced by naphthoresorcinol with $10 \mu \mathrm{g}$ per $3.0 \mathrm{ml}$ of glucuronic acid is reproducible over a period of seven days. The colour of the blank (curve 2) reaches a plateau which also is maintained for seven days after which the absorbance increases quite sharply. The results, therefore, illustrate that the reagent can be used up to a period of seven days but it is this author's suggestion that fresh MNR preparations be utilized. The stability of the MNR reagent is not as good compared to Nir's reagent which is proposed to be stable for a period of 3 months. However, Nir's reagent has approximately one-eighth the sensitivity of the MNR reagent.

The present method, therefore, provides the advantage of sensitivity which is a requirement for the determination of low concentrations of glucuronic and glucuronides in serum. The reagent is fairly stable and reproducible. The method proves to be more accurate at these low concentrations when compared to other methods. The method is flexible with respect to heating time and sample size. If glucuronic acid concentrations above $16.6 \mu \mathrm{g}$ per $3.0 \mathrm{ml}$ are to be determined, then a $30 \mathrm{~min}$ heating period and 
Legend to Figure 3

Fig. 3 stability study of the MNR reagent. The MNR procedure was performed regularly over a period of two weeks: Curve 1 , sample containing $10 \mu \mathrm{g}$ per $3.0 \mathrm{ml}$ of glucuronic acid, $90 \mathrm{~min}$ heating; Curve 2, blank containing $3.0 \mathrm{ml}$ of $\mathrm{H}_{2} \mathrm{O}, 90$ min heating. 


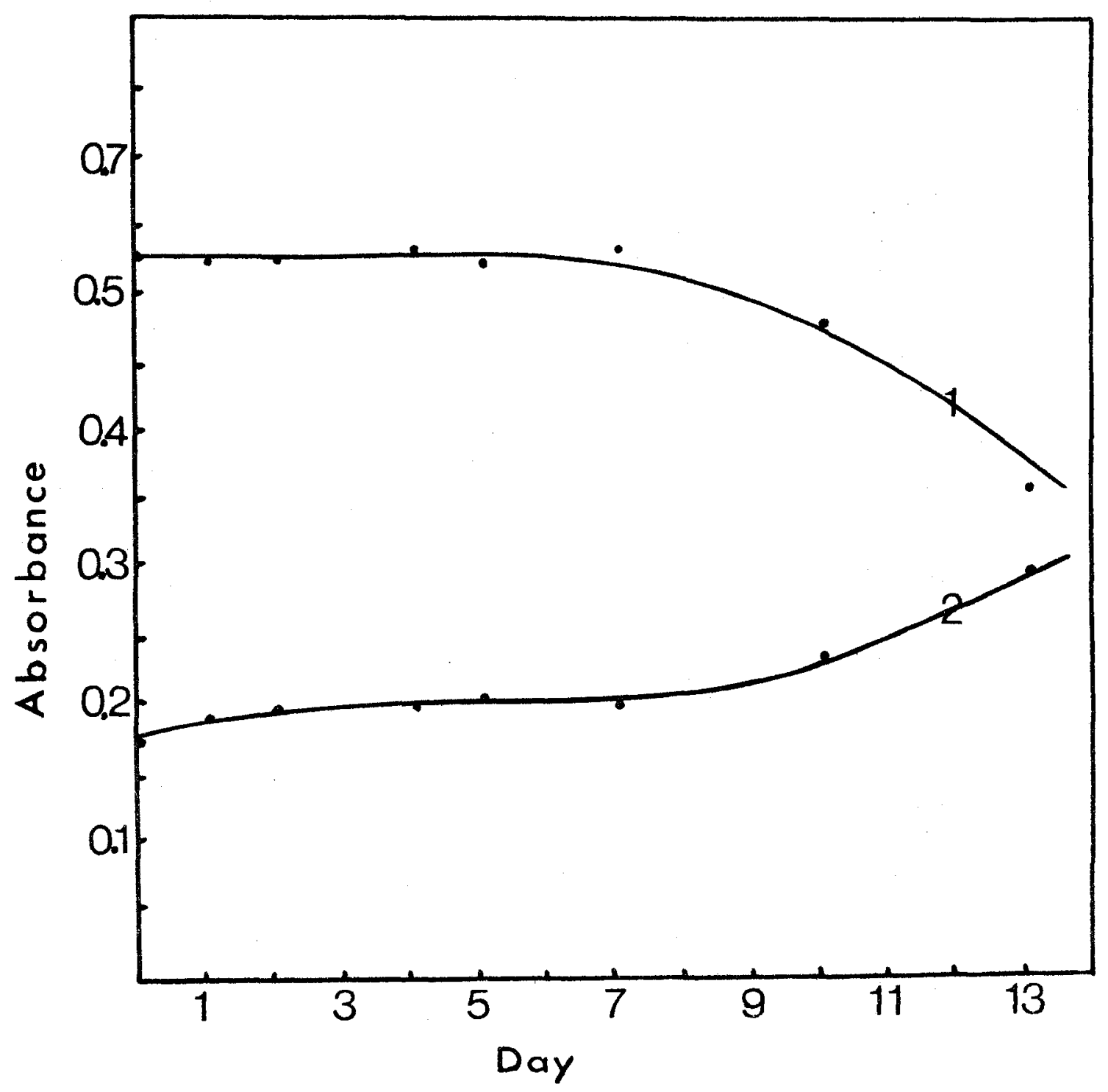


dilution of sample could be utilized to obtain results quickly and accurately. The time required to carry out a complete analysis in pure systems is one to two hours depending on heating time.

In the determination of both glucuronic acid and glucuronides in serum or urine, many investigators have reported that glucose, which is at much higher concentrations with respect to glucuronic acid (particularly in serum) interferes with the colour reaction $(31,59,60,62$, 76). Several authors have reported success in removing glucose from solutions with yeast $(77-79)$. This has been found to be too time consuming and the results were unsatisfactory $(31,60)$. An alternative was to compensate by adding known amounts of glucose to the standards (31, 80). This procedure was satisfactory when the glucose concentration was within normal limits (80 - $120 \mathrm{mg}$ per $100 \mathrm{ml}$ ). The obvious disadvantages in this procedure are the necessity to determine exactly the concentration of glucose in the samples and an increase in the complexity of preparing the standard solutions.

Fishman (62) was able to determine conjugated glucuronic acid in the presence of free glucuronic acid by oxidation of free glucuronic acid with hypoiodite to 
saccharic acid which is insensitive to the NR reaction. The hypoiodite reaction also oxidizes glucose to gluconic acid which is also insensitive to the NR reaction (84). Therefore, in this determination of conjugated glucuronic acid or glucuronide, glucose interference is eliminated. However, total glucuronic acid (free glucuronic acid plus glucuronide) cannot be determined accurately by this procedure since the hypoiodite reaction is not allowed to occur. (Glucose is not oxidized, therefore, interference does occur.) Free glucuronic acid cannot be determined accurately since it is calculated as the difference in the values for glucuronic acid before and after the oxidation procedure. The values for both total and free glucuronic acid would be too high. This method, as was mentioned previously, has been widely utilized and was reported to be inaccurate in the presence of high concen-trations of glucose $(75,76)$. In a later communication Fishman et al. (84) employed glucose oxidase to eliminate glucose interference. However, the procedure utilized a crude preparation of the enzyme which resulted in high blank readings, loss in sensitivity, an extended incubation period ( 3 hours), and tedious $\mathrm{pH}$ adjustments for the incubation procedure. 
In the present study glucose oxidase was also utilized. It was observed that crude preparations of the enzyme contained high concentrations of NR positive impurities, and consequently could not be employed. Glucose oxidase Type V from Sigma Chemical Company (1000 E.U. per $\mathrm{ml}$ ) was found to be most satisfactory in eliminating glucose interference. The incubation is performed before deproteinization in order to eliminate $\mathrm{pH}$ adjustments and to minimize as much as possible any contributions to the MNR colour reaction due to the enzyme preparation. Figure 4 illustrates the interferences one can expect from glucose when the glucose oxidase system is used to convert glucose to gluconic acid. Figure 4 (curve 1) exhibits a plateau region of absorbance between 150 to $270 \mathrm{mg} \%$ of glucose and then the absorbance increases with increasing glucose concentration. The interference at this plateau is equivalent to approximately $1.3 \mu \mathrm{g}$ of glucuronic acid. Curve 2 illustrates that the absorbance reaches a plateau between 100 to $450 \mathrm{mg} \%$ of glucose. The interference at this plateau is equivalent to approximately $0.45 \mu \mathrm{g}$ of glucuronic acid. The results, therefore, indicate that the interference in this plateau region is constant. Since glucose is converted to gluconic acid by the enzyme, 
44

Legend to Figure 4

Fig. 4 Glucose interference study with glucose oxidase:

Curve 1, $2.0 \mathrm{ml}$ samples, $90 \mathrm{~min}$ incubation, $3.0 \mathrm{ml}$ aliquot, $564 \mathrm{~nm}$; Curve 2, $1.0 \mathrm{ml}$ samples, $45 \mathrm{~min}$ incubation, $1.5-\mathrm{ml}$ aliquot, $564 \mathrm{~nm}$; Curve $3,1.0$

ml samples of gluconic acid, no enzyme, 1.5-ml aliquot, $564 \mathrm{~nm}$. 


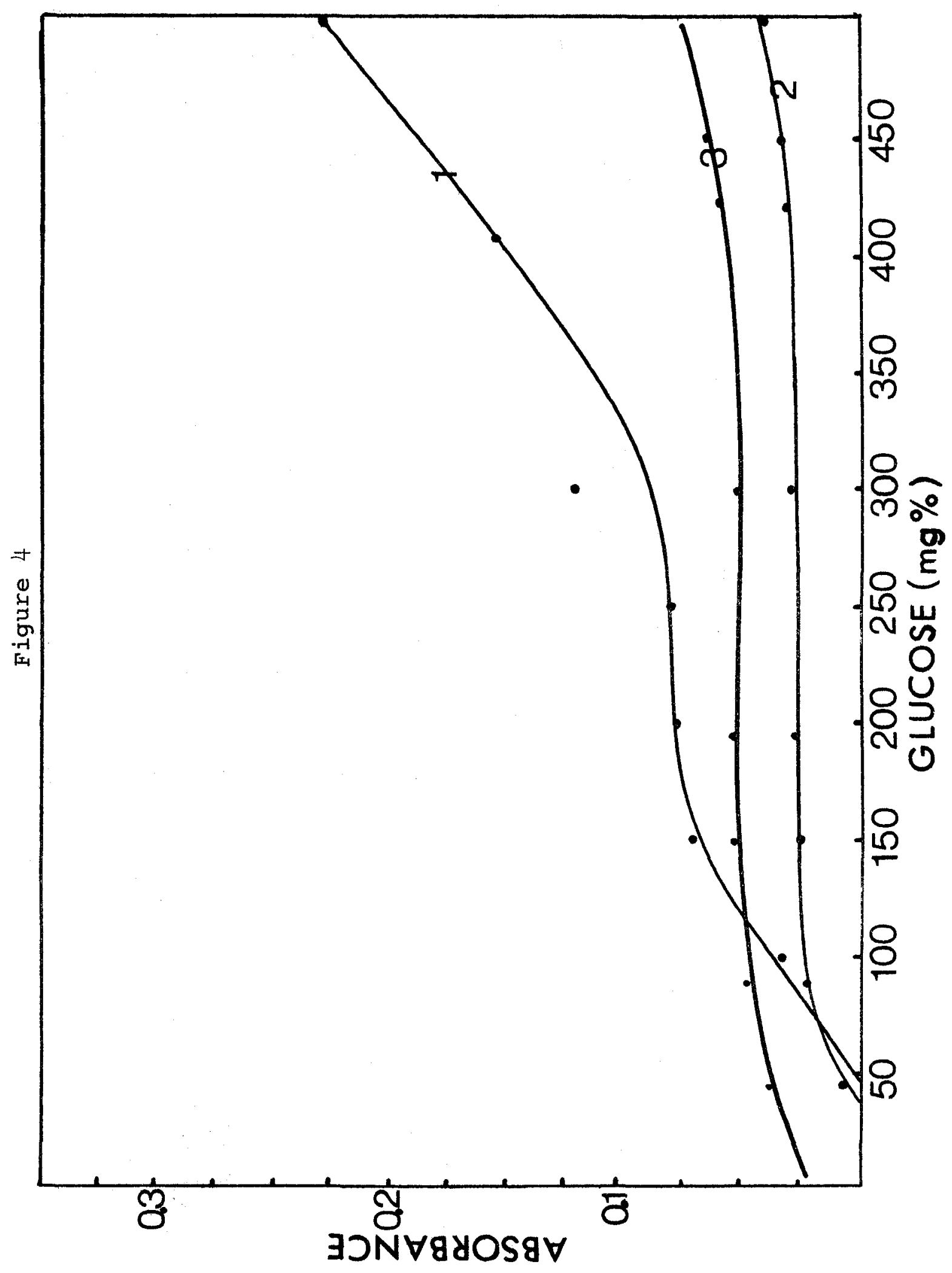


glucose oxidase, the behaviour illustrated in Fig. 4 (curve 2) results from gluconic acid interference since it was observed in this laboratory that gluconic acid is in fact NR positive at high concentrations (curve 3 ). The interference of pure gluconic acid samples (curve 3 ) at concentrations equivalent to the glucose samples displays a similar curve to that obtained with glucose samples treated with glucose oxidase. This interference is constant due to the fact that the MNR reagent simply does not quantitatively react with gluconic acid. The interference of $0.45 \mu \mathrm{g}$ of glucuronic acid equivalent can be eliminated completely by the addition of glucose and glucose oxidase to the blanks. The quantity of glucose added to the blank is not critical since the interference is constant in the range of 100 to $450 \mathrm{mg} \%$ of glucose. Furthermore, the necessity for pre-determining the glucose level in the samples is obviated. The blank would also eliminate any interferences resulting from the enzyme preparations. The total time of incubation is $45 \mathrm{~min}$ instead of 3 hours and no pH adjustments are necessary except for preparing the acetate buffer. The results of the quantitative determination of gluconic acid in the presence of $3 \mathrm{mg} \%$ of glucose are 
reported in Table II (samples 1 - 5). The errors involved are in the range of $\pm 4 \%$. Therefore, we can accurately determine low concentration of glucuronic acid in the presence of high concentrations of glucose.

In the determination of conjugated glucuronic acid free glucuronic acid must be eliminated. Fishman, as mentioned previously, utilized sodium hypoiodite to oxidize the free glucuronic acid to saccharic acid (62). Halogen reactions, in general, are susceptible to many sources of error (85). The reactions are light and $\mathrm{pH}$ sensitive. The procedure requires additional reagents and $\mathrm{pH}$ adjustments which are time consuming and tedious. To eliminate these sources of error and $\mathrm{pH}$ adjustments, $\mathrm{NaOH}$ is utilized to decompose free glucuronic acid to a product insensitive to the MNR reagent $(86,87)$. Table II (samples $6-8$ ) demonstrates that phenolphthalein mono- $\beta-$ glucuronide (P-Gide) can be quantitatively determined in the presence of glucuronic acid with an error of $-2.6 \%$. The absorption maximum for the product formed in this reaction occurs at $564 \mathrm{~nm}$ (Fig. 1, curve 1) and at 510 nm for the blank (curve 3). Therefore, NaOH does not alter the absorption maximum of the NR pigment. The reaction requires $20 \mathrm{~min}$ heating in a boiling water bath. 
48

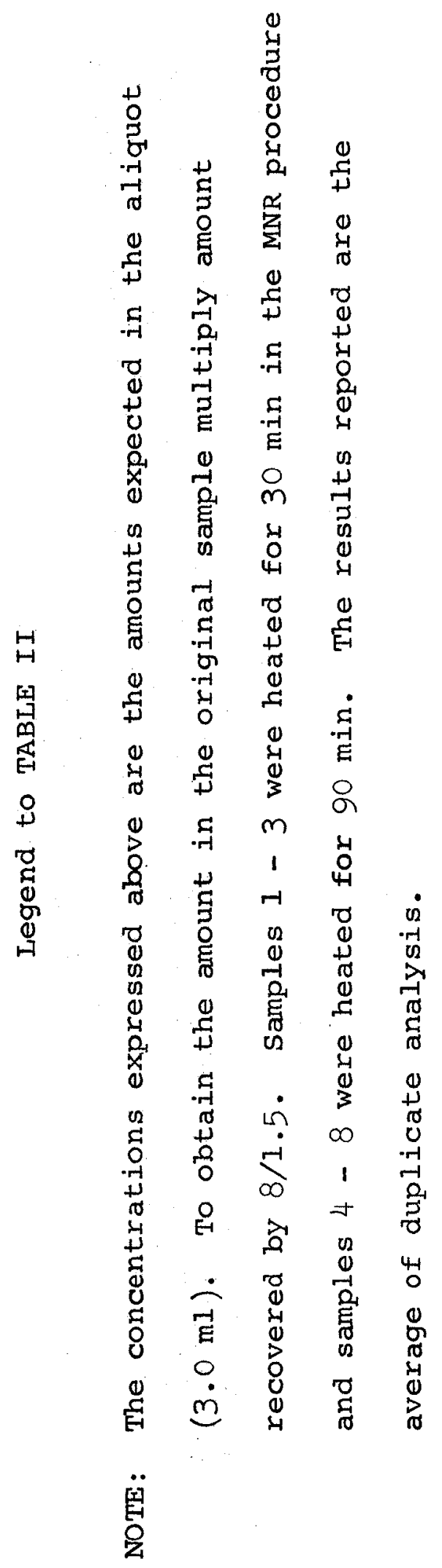




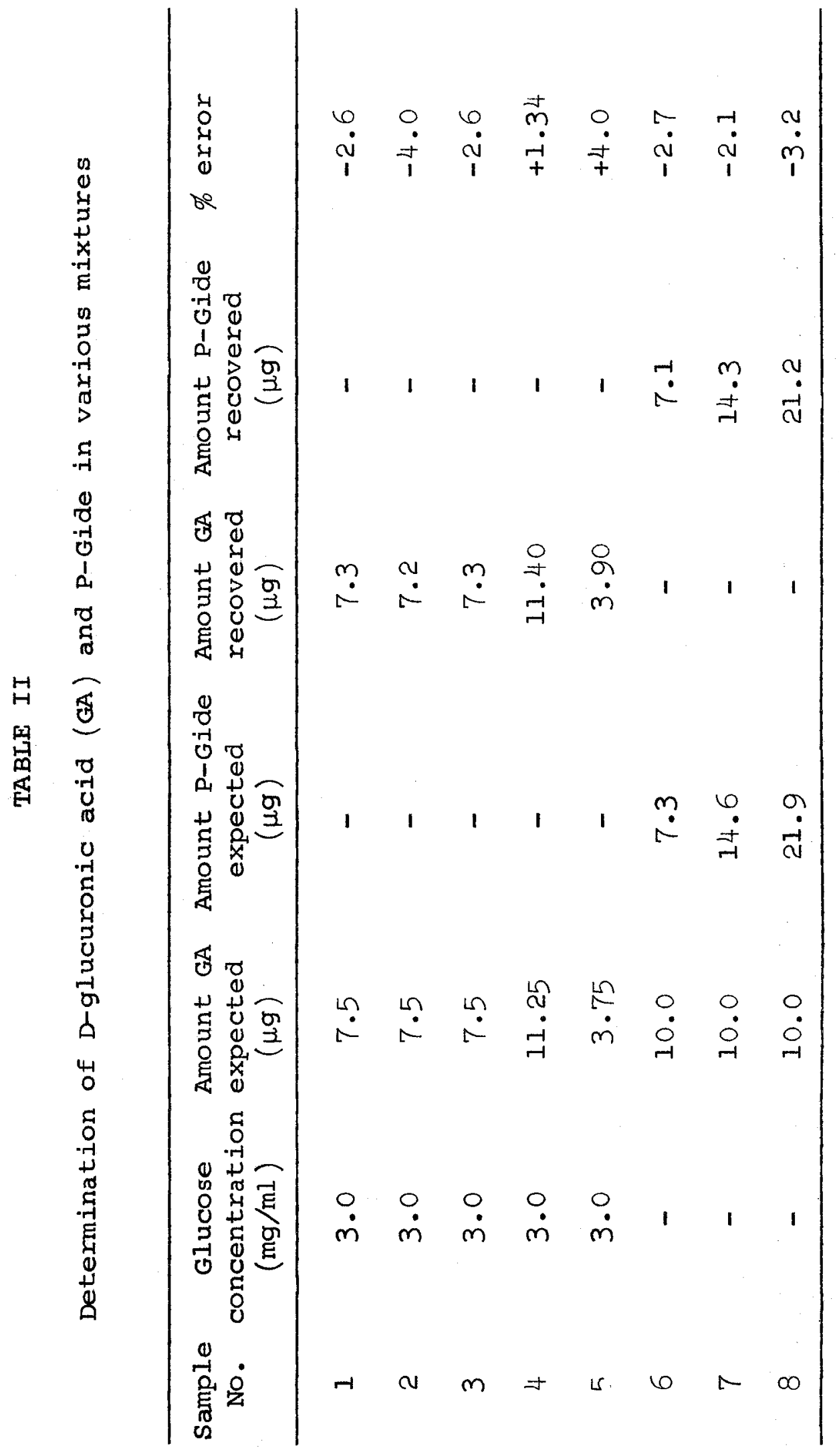


The above procedure is accurate and has the following advantages: no $\mathrm{pH}$ adjustments are required; the only additional reagent required is $\mathrm{NaOH}$; the method requires less time and is not as sensitive to reaction conditions as the hypoiodite method.

In order to establish the reliability of the procedures, quantitative determinations were performed on synthetic mixtures. Glucuronic acid and P-Gide (total and conjugated) were determined in the presence of 3 mg per ml glucose. The procedure is outlined in the flow diagram (Fig. 5) and the results are reported in Table III. The error ranges from -0.5 to $-5.4 \%$ in the optimum concentration range of the MNR procedure. The error is at a maximum at low concentrations (-9.2\%) but the deviation at these low concentrations is less than $\pm 0.3 \mu \mathrm{g}$ per $3.0 \mathrm{ml}$

Fishman ( 62 ) and others determine the amount of glucuronic acid and glucuronides from standard curves of glucuronic acid. This requires that the standards be treated in the same fashion as the samples and that they are analyzed simultaneously with the samples. This must be done since the NR reaction varies with changes in reaction conditions and the reagent, itself, undergoes 
51

Legend to Figure 5

Fig. 5 Flow diagram outlining procedural steps for a single sample. Volume (ml) is marked in parentheses and effect of dilution is recorded by arrow above volume. $\Longrightarrow$ Urine; $\longrightarrow$ synthetic sample or serum. "Total" refers to total Glucuronic acid and glucuronide and "Conjugate" refers to glucuronide. 
Figure 5

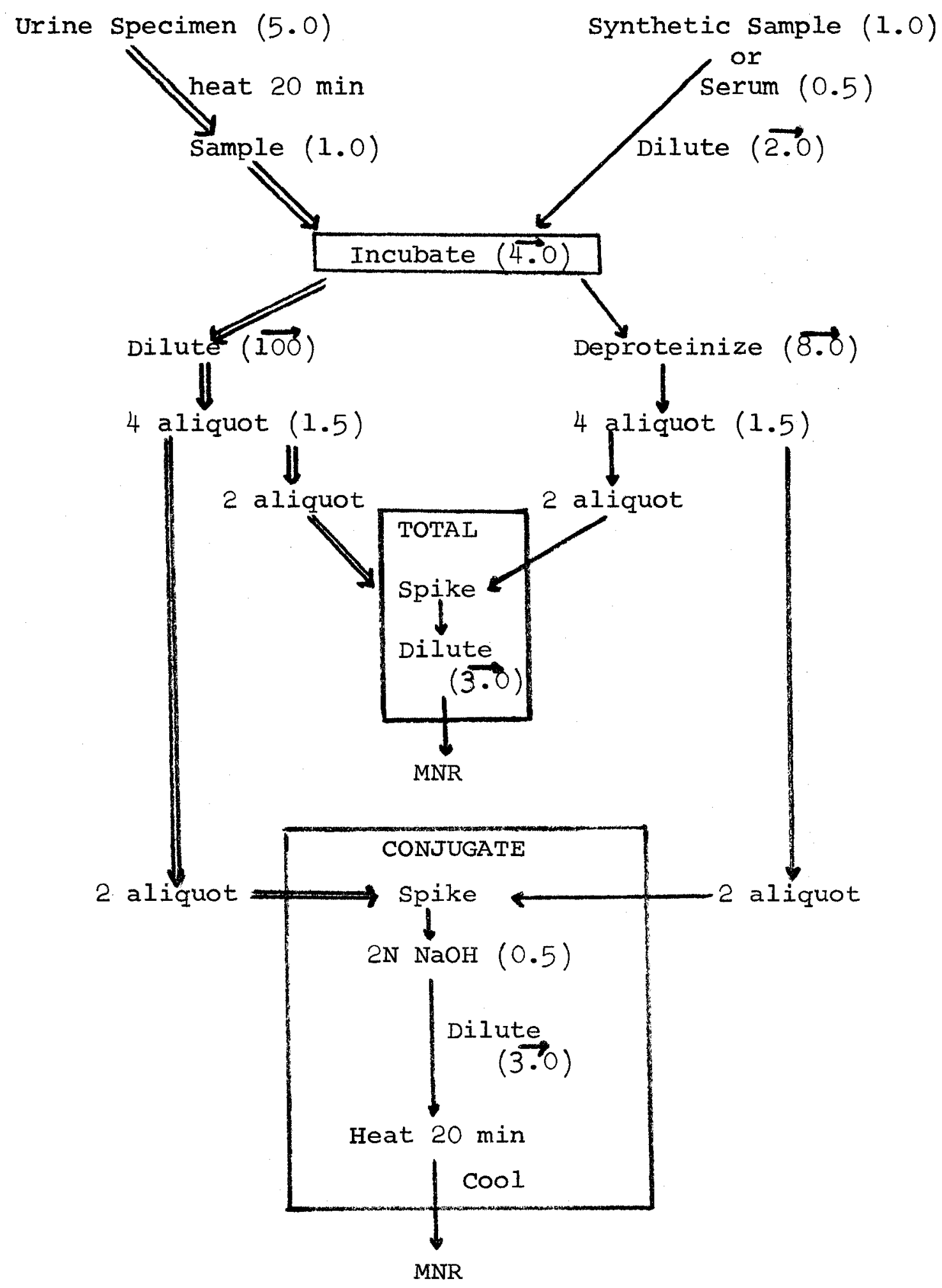


TABLE III

Determination of glucuronides and glucuronic acid in synthetic mixtures

\begin{tabular}{|c|c|c|c|c|c|c|}
\hline \multirow[b]{2}{*}{$\begin{array}{c}\text { Sample } \\
\text { No. }\end{array}$} & \multicolumn{3}{|c|}{ TOTAL } & \multicolumn{3}{|c|}{ CONJUGATED } \\
\hline & $\begin{array}{l}\text { Expected } \\
(\mu g / 3 \mathrm{ml})\end{array}$ & $\begin{array}{r}\text { Recovered } \\
(\mu \mathrm{g} / 3 \mathrm{ml})\end{array}$ & $\begin{array}{c}\% \\
\text { error }\end{array}$ & $\begin{array}{l}\text { Expected } \\
(\mu \mathrm{g} / 3 \mathrm{ml})\end{array}$ & $\begin{array}{l}\text { Recovered } \\
(\mu \mathrm{g} / 3 \mathrm{ml})\end{array}$ & $\begin{array}{c}\% \\
\text { error }\end{array}$ \\
\hline 1 & 2.06 & 1.9 & -9.2 & 1.12 & 0.95 & -6.2 \\
\hline 2 & 5.05 & 4.8 & $-5 \cdot 0$ & 4.11 & 3.95 & $-3 \cdot 9$ \\
\hline 3 & 11.04 & 10.8 & -2.1 & 10.10 & 10.05 & -0.5 \\
\hline 4 & 14.03 & 13.8 & -1.6 & 11.30 & 11.15 & $-1 \cdot 3$ \\
\hline 5 & 8.97 & 8.6 & -4.1 & 13.09 & 12.94 & -1.2 \\
\hline 6 & 7.11 & $7 \cdot 24$ & +2.0 & 5.23 & 4.95 & +5.4 \\
\hline
\end{tabular}

NOI'E: The amounts expressed above denote the concentrations expected in the $1.5-\mathrm{ml}$ aliquots diluted to $3.0 \mathrm{ml}$ which were utilized in the MNR reaction. To obtain amount in original sample multiply the concentrations by $8 / 1.5$. The results reported are the average of duplicate analysis except in sample one where the recovery was determined from extrapolation of the curve to the $\mathrm{x}$-axis. 
changes with time $(31,62,88)$. The calibration curve, however, cannot account for any endogenous reactions occurring in the system as a result of added reagents. It does account for the effects of reagents on the particular species being analyzed. The determination is also restricted to the error limits imposed by the calibration curve. The method of standard addition has the following advantages: increased accuracy at low endogenous concentrations of glucuronic acid; takes into consideration any endogenous reactions; does not require the preparation of a standard curve; the curve obtained from one sample utilizing this technique can then be employed as the standard curve for unknown samples; elimination of tedious preparations of standards to account for glucose interference and other endogenous interferences. All that is required is the preparation of the appropriate blank for the particular system. The blank system consists of glucose and glucose oxidase. The spike solution is prepared from a P-Gide stock solution. The variation in concentration from our standard curve in the pure system was $\pm 0.5 \mu \mathrm{g}$ per $3 \mathrm{ml}$, yet, employing the method of standard addition the variation at concentration range was $-0.3 \mu \mathrm{g}$ and $-0.16 \mu \mathrm{g}$ per $3.0 \mathrm{ml}$ at the maximum 
and minimum, respectively. An example of the type of extrapolation required is illustrated in Fig. 6. The curves for total and conjugated glucuronic acid are linear and parallel which demonstrates obedience to Beer's law. The curve should be parallel since both curves originate from the same sample, except under one set of conditions the endogenous free glucuronic acid is decomposed with $\mathrm{NaOH}$.

The method as outlined in Fig. 6 was studied for precision or reproducibility in both serum and urine. Before this study was attempted in serum it was essential to investigate whether the P-Gide could be completely recovered from serum. This was considered necessary since it has been established that free glucuronic acid is in fact adsorbed or coprecipitated with proteins $(70$, 76). Therefore, samples of pooled sera were spiked before and after deproteinization. The samples were spiked in such a manner that the concentration of P-Gide in the final aliquots would be the same if no adsorption occurred. Figure 7 illustrates that adsorption of the P-Gide does in fact occur. If adsorption had not occurred curves 1,2 would be identical as would curves 3, 4. The amount recovered was determined by employing 
Legend to Figure 6

Fig. 6 Determination of total and conjugated glucuronic acid in synthetic mixtures by method of standard addition. The curves illustrate the method of extrapolation; Curve 1 total glucuronic acid; Curve 2, conjugated glucuronic acid. 


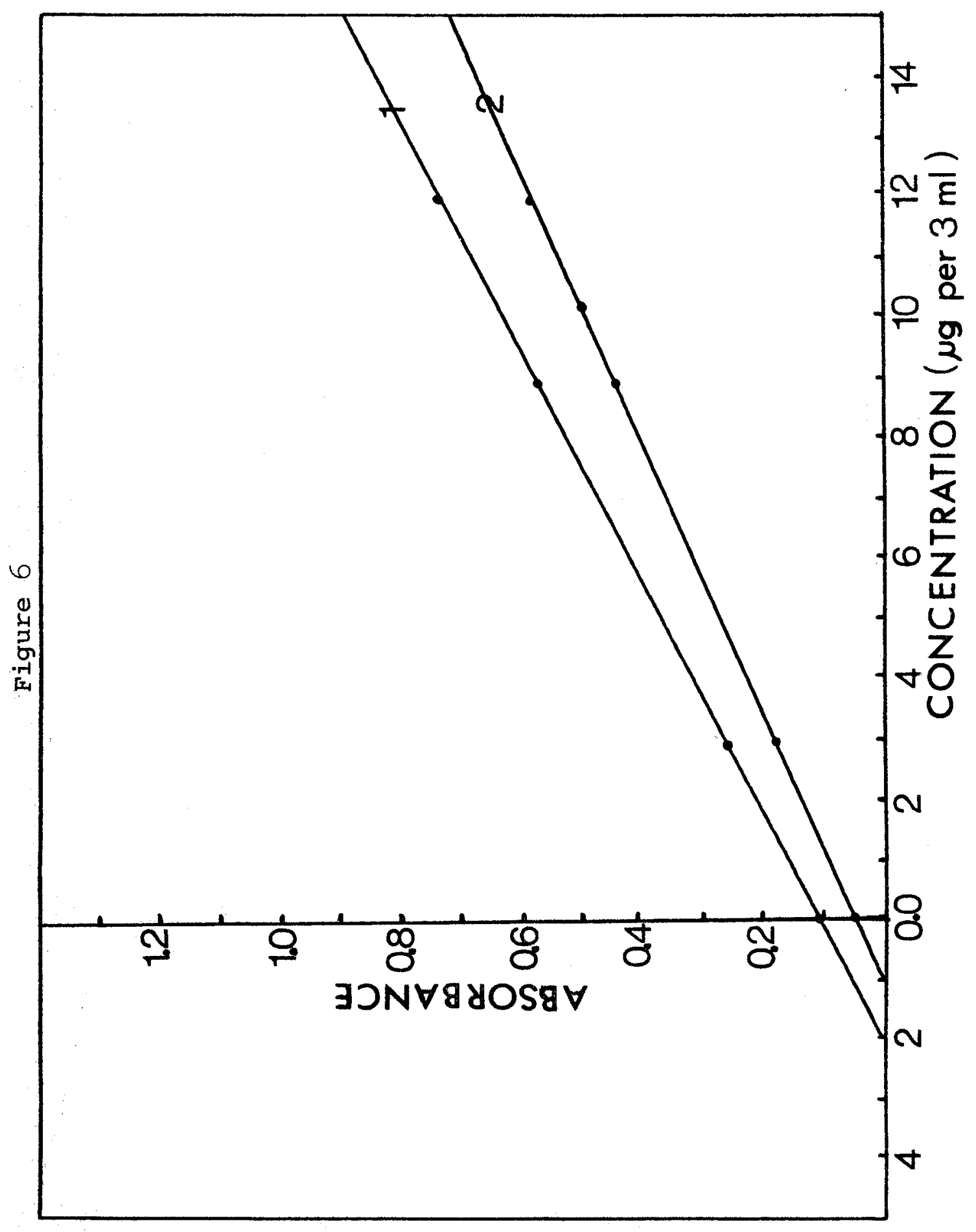


58

\section{Legend to Figure 7}

Fig. 7 Curves illustrate the loss of P-Gide on deproteinization in the determination of conjugated glucuronic acid: Curve $1,1.0 \mathrm{ml}$ samples, spiked after deproteinization; Curve 2, $1.0 \mathrm{ml}$ samples, spiked before deproteinization; Curve $3,0.5 \mathrm{ml}$ samples, spiked before deproteinization; Curve 4, $0.5 \mathrm{ml}$ samples, spiked after deproteinization. 


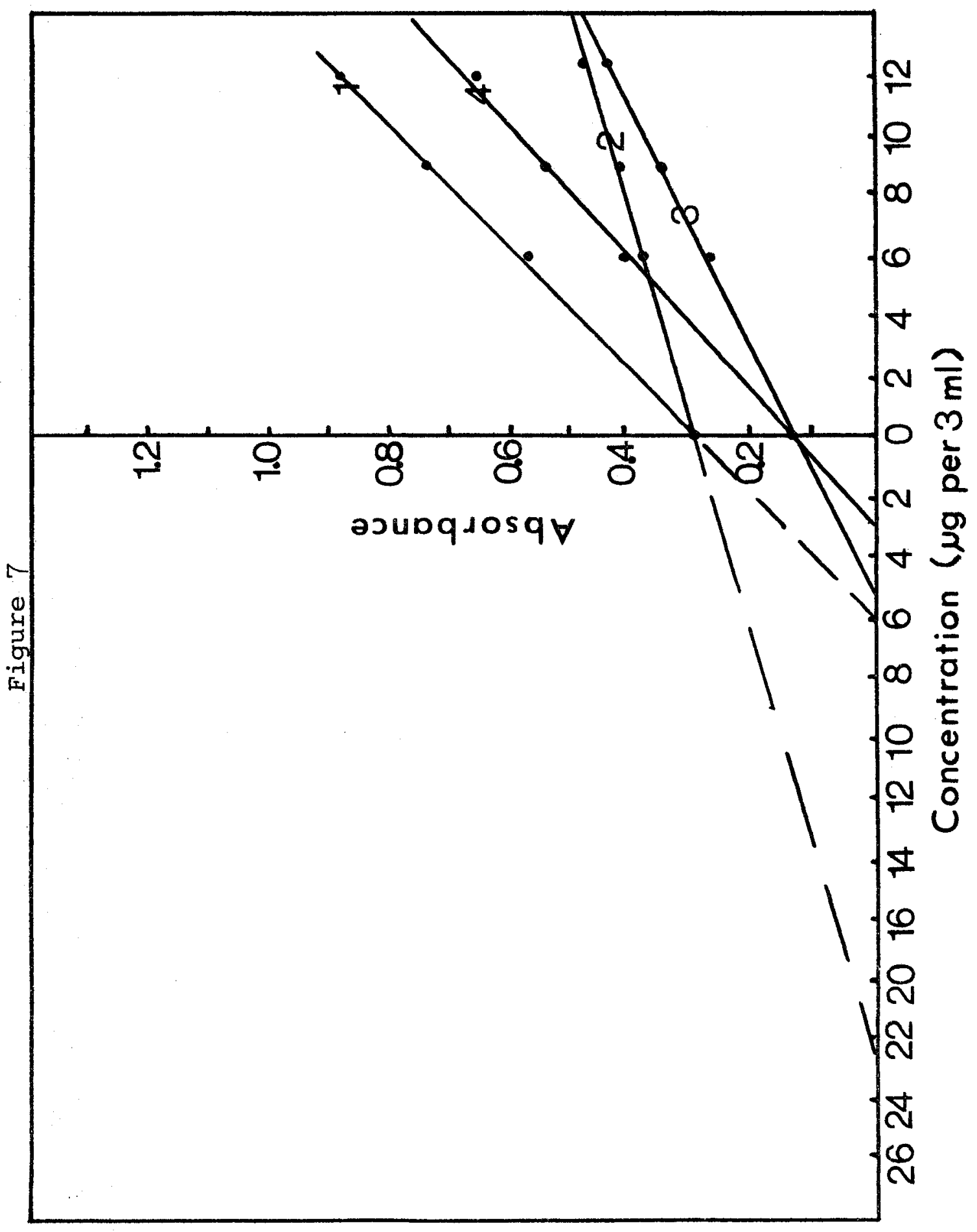


the curve obtained from spiking after deproteinization as the standard curve. The results are reported in Table IV. The amounts recovered from 1.0-m1 samples of serum varied from 53.5 to $73.2 \%$ with a mean recovery of $62.7 \%$.

To determine more conclusively that per cent recovery is related to protein concentration, $0.5-\mathrm{ml}$ and $0.25-\mathrm{ml}$ samples of serum were utilized instead of $1.0 \mathrm{ml}$. If adsorption is a factor of protein concentration, the recoveries should increase and the slopes of the curves obtained from spiking before and after deproteinization should approach each other. This would be exemplified by an increase in the slope of the curves utilizing 0.5-ml and 0.25-ml samples which were spiked before deproteinization. Curve 3 (Fig. 7) illustrates an increase in slope in comparison to curve $2(0.5 \mathrm{ml}$ used as example). If recoveries did not increase, all the respective curves obtained from the data before and after deproteinization would be parallel. This is true for curvessl and 4 which were obtained from samples spiked after deproteinization but not so for curves 2 and 3 which were obtained from samples spiked before deproteinization. The recoveries in the system (Table IV, samples 5-8) 
Legend to TABLE IV

Recovery Studies in Serum

a Samples 1 - 4 employed $1.0 \mathrm{ml}$ serum

b Samples 5 - 8 employed $0.5 \mathrm{ml}$ serum

c Samples 9 - 12 employed $0.25 \mathrm{ml}$ serum

d Samples 13 - 16 employed $0.5 \mathrm{ml}$ serum and sodium deoxycholic acid

NOTE: The amounts recovered in samples $1,5,9$, and 13 were determined by the method of standard addition. Recoveries in other samples were determined from curve obtained after deproteinization and are the result of duplicate analysis. 
TABLE IV

Recovery studies in Serum

\begin{tabular}{|c|c|c|c|c|c|c|}
\hline \multirow[b]{2}{*}{ Sample } & \multicolumn{3}{|c|}{ TOTAL } & \multicolumn{3}{|c|}{ CONJUGATED } \\
\hline & $\begin{array}{l}\text { Amount } \\
\text { Expected } \\
(\mu \mathrm{g} / 3 \mathrm{ml})\end{array}$ & $\begin{array}{c}\text { Amount } \\
\text { Recovered } \\
(\mu \mathrm{g} / 3 \mathrm{ml})\end{array}$ & $\begin{array}{c}\% \\
\text { reco- } \\
\text { very }\end{array}$ & $\begin{array}{l}\text { Amount } \\
\text { Expected } \\
(\mu \mathrm{g} / 3 \mathrm{ml})\end{array}$ & $\begin{array}{l}\text { Amount } \\
\text { Recovered } \\
(\mu \mathrm{g} / 3 \mathrm{ml})\end{array}$ & $\begin{array}{c}\% \\
\text { reco- } \\
\text { very }\end{array}$ \\
\hline $1^{a}$ & - & 9.9 & - & - & 6.00 & - \\
\hline 2 & 15.84 & 11.6 & 73.2 & 11.94 & 7.95 & 66.5 \\
\hline 3 & 18.87 & 12.5 & 66.2 & 14.97 & 8.45 & 56.4 \\
\hline 4 & 22.24 & 13.5 & 60.7 & 18.34 & 9.83 & 53.5 \\
\hline $5^{b}$ & - & 4.90 & - & - & 3.00 & - \\
\hline 6 & 9.84 & 8.20 & 83.3 & 8.94 & 5.80 & 64.9 \\
\hline 7 & 13.87 & 9.65 & 69.5 & 11.97 & 7.80 & 65.2 \\
\hline 8 & 17.24 & 11.3 & 65.5 & 15.34 & 10.6 & 69.1 \\
\hline $9^{c}$ & - & 2.80 & - & - & 0.80 & - \\
\hline 10 & 6.78 & 5.80 & 85.5 & 4.78 & 3.8 & 79.5 \\
\hline 11 & 8.80 & 7.50 & 85.2 & 6.80 & 5.40 & 79.4 \\
\hline 12 & 11.05 & 9.40 & 85.1 & 9.05 & 7.4 & 81.8 \\
\hline $13^{d}$ & - & 3.00 & - & - & 1.7 & - \\
\hline 14 & 6.18 & 5.50 & 88.9 & 4.88 & 4.0 & 81.9 \\
\hline 15 & 7.80 & 6.60 & 84.6 & 6.50 & 5.20 & 80.0 \\
\hline 16 & 9.80 & 8.10 & 82.6 & 8.30 & 6.90 & 83.1 \\
\hline
\end{tabular}


varied from 64.9 to $83.3 \%$ with a mean recovery of $70.2 \%$. Therefore, there was in increase in recoveries in utilizing 0.5-ml samples when compared to 1.0-ml samples. Recoveries were increased further when $0.25-\mathrm{ml}$ samples were utilized (Table IV, samples $9-12$ ). The recoveries ranged from 79.4 to $85.5 \%$ with a mean value of $82.8 \%$. The difference in slopes reported in Table $\mathrm{V}$, however, illustrate this increase much more conclusively. The results indicate very little change in the slopes of curves obtained from samples spiked after deproteinization but the slopes approximately increased by factors of two and three for 0.5 and $0.25-\mathrm{ml}$ samples, respectively. In order to obtain a more accurate value of the amount of free glucuronic acid and bound glucuronic acid in serum the recommended procedure for deproteinization is dialysis (70). However, this method experiences recoveries between $90-95 \%(70)$ but requires a minimum of three hours.

Protein denaturing agents (Triton $\mathrm{x}-100$, urea, and sodium deoxycholic acid) were utilized in an attempt to free the glucuronic acid (free and combined) from the protein and therefore, increase our recoveries. The results obtained in preliminary studies with Triton X-100 indicated that this reagent affected the MNR colour 
TABLE V

Effect of protein concentration on slopes

\begin{tabular}{|c|c|c|c|c|}
\hline \multirow{3}{*}{$\begin{array}{c}\text { Volume } \\
\text { sample } \\
\text { (ml) }\end{array}$} & \multicolumn{4}{|c|}{ SLOPE } \\
\hline & \multicolumn{2}{|c|}{ TOTAL } & \multicolumn{2}{|c|}{ CONJUGATED } \\
\hline & $\begin{array}{c}\text { After } \\
\text { deprotein- } \\
\text { ization }\end{array}$ & $\begin{array}{c}\text { Before } \\
\text { deprotein- } \\
\text { ization }\end{array}$ & $\begin{array}{c}\text { After } \\
\text { deprotein- } \\
\text { ization }\end{array}$ & $\begin{array}{c}\text { Before } \\
\text { deprotein- } \\
\text { ization }\end{array}$ \\
\hline 1.0 & 0.045 & 0.013 & 0.050 & 0.014 \\
\hline 0.5 & 0.047 & 0.025 & 0.046 & 0.024 \\
\hline 0.25 & 0.050 & 0.039 & 0.049 & 0.037 \\
\hline $0.5^{\mathrm{a}}$ & 0.059 & 0.045 & 0.061 & 0.043 \\
\hline
\end{tabular}

a Sample treated with sodium deoxycholic acid 
development and therefore was not employed. Recoveries with urea utilizing $0.25-\mathrm{ml}$ samples of serum did not improve compared to normal samples (Table IV, samples 9 - 12). Sodium deoxycholic acid, however, did cause an increase in recovery as reported in Table IV, samples 13 16. The recoveries ranged from 80.0 to $88.9 \%$ with a mean value of $83.5 \%$. These results compared with recoveries obtained with similar samples which were not treated with sodium deoxycholic acid (Table IV, samples 5 - 8) indicate an increase of $13 \%$ recovery in the mean values. Therefore, recoveries can be increased employing sodium deoxycholic acid. However, this increase is not substantial compared to recoveries obtained utilizing $0.25-\mathrm{ml}$ samples (Table IV, samples $9-12$ ) and therefore, the time and effort required with sodium deoxycholic acid is not warranted. Therefore, I suggest that 0.5 or $0.25-\mathrm{ml}$ samples of serum be utilized depending on the final concentration of glucuronide being determined. This should not be any lower than $1 \mu \mathrm{g}$ per 3.0 milliliters.

Reproducibility data employing the present method in the determination of total and conjugated glucuronic acid in serum are reported in Table VI. The reproducibility is $\pm 0.2 \mu \mathrm{g}$ per $3 \mathrm{ml}$ of aliquot and the results 
TABLE VI

Determination of glucuronic acid and glucuronide in serum

\begin{tabular}{ccccccc}
\hline \multirow{2}{*}{ Sample } & \multicolumn{2}{c}{ TOTAL } & & \multicolumn{2}{c}{ CONJUGATED } & FREE \\
\cline { 2 - 3 }$(\mu \mathrm{g} / 3 \mathrm{ml})$ & $\mathrm{mg} \%$ & & $\begin{array}{c}\text { found } \\
(\mu \mathrm{g} / 3 \mathrm{ml})\end{array}$ & $\mathrm{mg} \%$ & $\mathrm{mg} \%$ \\
\hline $1^{\mathrm{a}}$ & $9.9 \pm 0.2$ & $5.3 \pm 0.1$ & $6.0 \pm 0.15$ & $3.2 \pm 0.1$ & 2.1 \\
$2^{\mathrm{b}}$ & $4.9 \pm 0.2$ & $5.2 \pm 0.2$ & $3.0 \pm 0.2$ & $3.2 \pm 0.2$ & 2.0 \\
3 & $4.1 \pm 0.2$ & $4.4 \pm 0.2$ & $3.2 \pm 0.1$ & $2.4 \pm 0.1$ & 1.9 \\
\hline
\end{tabular}
a Sample volume was $1.0 \mathrm{ml}$
b Sample 2 and 3 utilized $0.5 \mathrm{ml}$ serum samples

NOTE: Pooled sera was employed in this study. To

obtain amount in original sample multiply amount found by $8 / 1.5 \times$ reciprocal of the volume taken. The results reported are the average of five determinations. 
are in fair agreement with reported ranges for total and conjugated glucuronic acid in serum (61). However, due to the problem of adsorption, ranges could vary with the deproteinization procedure employed. It is also important to note that pooled sera was utilized since the main concern in this study was to establish precision.

Urine does not require deproteinization and the reproducibility reported in Table VII is approximately $\pm 0.2 \mu \mathrm{g}$ per $3.0 \mathrm{ml}$. Due to the high dilution requirement, this factor results in a deviation of $\pm 16 \mathrm{mg}$ per 24-hour sample of urine.

To determine the variation, if any, in reproducibility from day to day with fresh and aged reagent, all the curves obtained in the urine study were compared to each other. Figure 8 (curve 1 ) illustrates that these curves coincided very well, which demonstrates that the system is reproducible, or that little or no change is observed when fresh and aged reagent (not more than 3 days old) is utilized. To determine the reproducibility throughout the entire study, the curves from the pure and biological systems were compared to each other. Figure 8 (curve 3 ) corresponds to the system in pure solutions. The results obtained from the serum samples coincided with the urine 
TABLE VII

Determination of Glucuronide and glucuronic acid in urine

\begin{tabular}{|c|c|c|c|c|c|}
\hline \multirow[b]{2}{*}{ Sample } & \multicolumn{2}{|c|}{ TOTAL } & \multicolumn{2}{|c|}{ CONJUGATED } & \multirow{2}{*}{$\frac{\text { FREE }}{24 \text { hg/ hour }}$} \\
\hline & $\begin{array}{l}\text { found } \\
\mu \mathrm{g} / 3.0 \mathrm{ml}\end{array}$ & $\begin{array}{c}24^{\mathrm{mg} /} \text { hour } \\
\text { hour }\end{array}$ & $\begin{array}{l}\text { found } \\
\mu \mathrm{g} / 3.0 \mathrm{ml}\end{array}$ & $\begin{array}{c}\mathrm{mg} / \\
24 \text { hour }\end{array}$ & \\
\hline $1^{a}$ & $9.5 \pm 0.04$ & $633 \pm 3$ & $4.7 \pm 0.35$ & $313 \pm 23$ & 320 \\
\hline $2^{b}$ & $6.8 \pm 0.3$ & $544 \pm 24$ & $5.0 \pm 0.2$ & $400 \pm 16$ & 144 \\
\hline $3^{b}$ & $4.6 \pm 0.13$ & $644 \pm 18$ & $3.5 \pm 0.23$ & $490 \pm 32$ & 154 \\
\hline
\end{tabular}

a 1.5-ml aliquots utilized for MNR

b 1.O-ml aliquots utilized for MNR

NOTE: The concentrations reported are the average of five determinations. To determine amount in original sample multiply amount found by $(1 / 1.5$ or 1$)$ times $100.1 .5-$ or $1.0-\mathrm{ml}$ alıquots are taken but are diluted to 3.0 $\mathrm{ml}$ in the MNR procedure. 
69

Legend to Figure 8

Fig. 8 Comparison of the Beer's law curves obtained throughout this study. Curve I was the result of all the data obtained in the biological systems. Curve 2 is the composite curve between the pure and applied systems. Curve 3 was obtained from the Beer's law study in the pure system (90 min heating). 


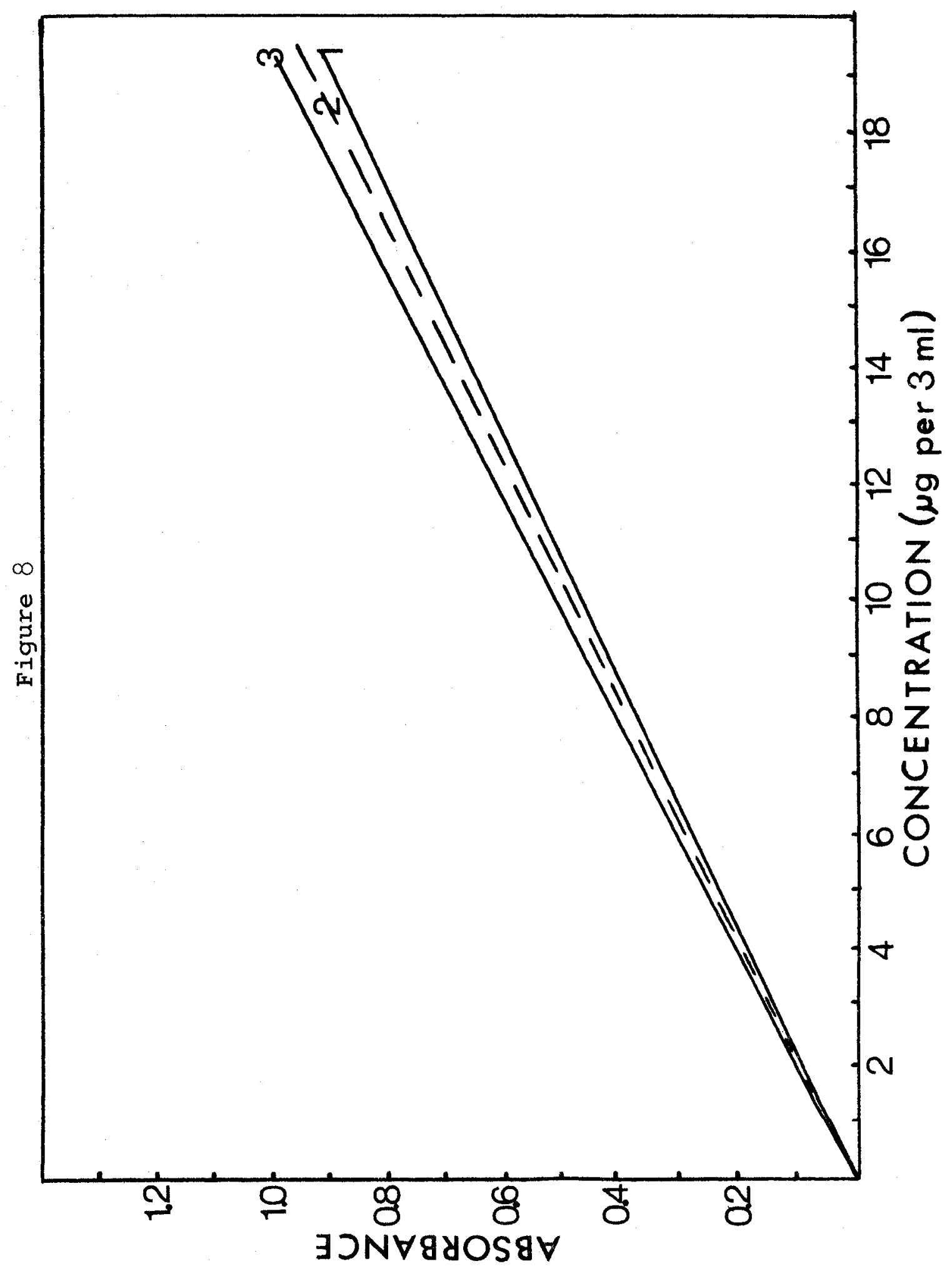


curve (curve 1). Therefore, the two curves (2 and 3 ) have established or defined the limits of variance over the entire study employing the MNR procedure. Curve 2 is a composite curve which was drawn and could be employed as the calibration curve for all systems with a maximum error limit of not more than $\pm 5 \%$. This demonstrates that the procedure is reproducible over a period of time, and that little variation occurs due to different reagent preparations and matrices of the systems under investigation. This provides an obvious advantage over other systems, since in the past, the NR reagent sensitivity increased with age, and since no two reagent preparations are exactly alike, different results were obtained with fresh reagents (88).

B. Titrimetric Determination of Glucose, Galactose, and Xylose with $\mathrm{N}$-Bromosuccinimide N-Bromosuccinimide (NBS) has been applied as an agent for allylic brominations. This type of halogenation is presently known as the Wohl-Ziegler reaction (89). An excellent review on this subject has been published by Djerassi (90). Under various conditions, N-halo compounds also react with olefins to add bromine to the double bond, 
or they act as a source of hypohalous acid in aqueous solution. Compounds belonging to this group include $\mathrm{N}$-chlorosuccinimide, $\mathrm{N}$-iodosuccinimide, and $\mathrm{N}$-bromophthalimide. Aside from the advantages of these compounds as halogenating agents, several of them have been found to be useful for oxidations and dehydrogenations. The reactions and uses of $\mathrm{N}$-bromosuccinimide have been reviewed in 1951 by waugh (91) and an excellent survey of the chemistry of this compound has been published by Horner (92). Therefore, we investigated the possibility of utilizing NBS as the oxidizing agent to eliminate glucose interference in the MNR reactions. Our approach was first to establish a procedure employing NBS to quantitatively determine glucose in pure systems and then apply the procedure to the MNR reaction in biological fluids. However, after having quantitized the procedure for glucose, it was discovered that tne excess NBS interfered with the colour development of the MNR reaction and attempts to eliminate this excess with cysteine, thiourea, and thioacetamide were to no avail. We then became interested in applying NBS to determination of other carbohydrates such as galactose, ribose, xylose, and mannose. We were able to quantitate the method for 
glucose, galactose, and xylose but were unable to do so for ribose and mannose which probably results from stereochemical considerations.

The products developed are essentially the same for all three sugars except that the optimum pH or basicity varied with each sugar. The procedure is thought to proceed as outlined in the following reaction:

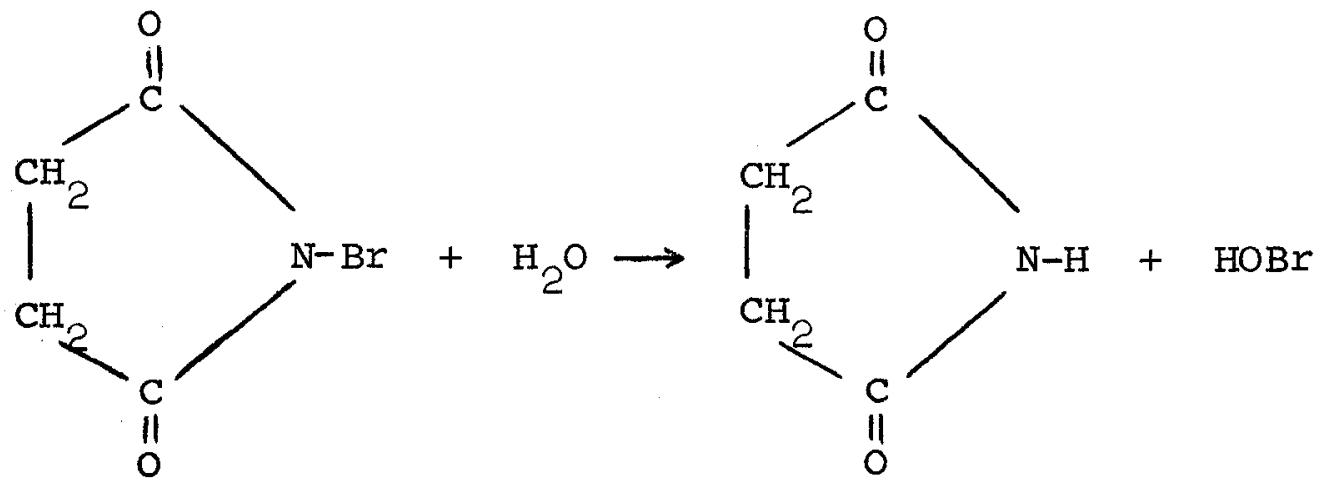

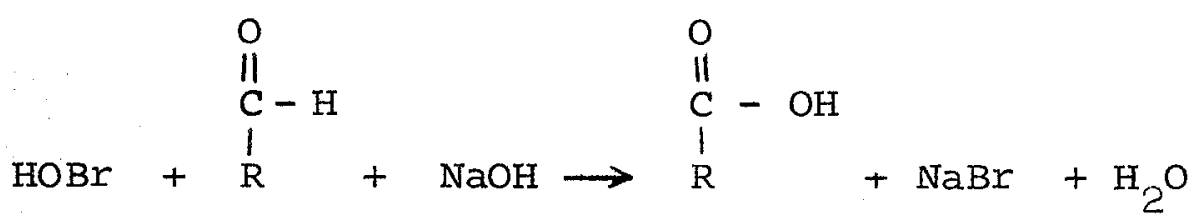

$(\mathrm{ex}) \mathrm{HOBr}+2 \mathrm{I}^{-}+2 \mathrm{HCl} \rightarrow \mathrm{I}_{2}+\mathrm{Br}^{-}+2 \mathrm{Cl}^{-}+\mathrm{H}_{2} \mathrm{O}$

$$
\begin{gathered}
\mathrm{I}_{2}+2 \mathrm{NaOH}(\mathrm{ex}) \rightarrow \mathrm{NaOI}+\mathrm{NaI}+\mathrm{H}_{2} \mathrm{O} \\
\mathrm{OI}^{-}+\mathrm{I}^{-}+2 \mathrm{HCl} \longrightarrow \mathrm{I}_{2}+2 \mathrm{Cl}^{-}+\mathrm{H}_{2} \mathrm{O} \\
\mathrm{I}_{2}+2 \mathrm{~S}_{2} \mathrm{O}_{3}^{-2} \rightarrow \mathrm{S}_{4} \mathrm{O}^{-2}+2 \mathrm{I}^{-}
\end{gathered}
$$


NBS hydrolyzes in water (equation 1) to form succinimide and hypobromous acid (93). Hypobromous acid in the presence of base oxidizes the aldehydic group to a carboxylic group (equation 2). The excess hypobromous acid oxidizes iodide to iodine which is then titrated in the usual manner with standard sodium thiosulfate using starch as indicator. The calculations involved have been described in section B (Chapter II).

The reaction proceeds at room temperature and the $\mathrm{pH}$ is very critical. The $\mathrm{pH}$ optimum range for each sugar is reported in Table VIII. The recovery study for glucose illustrated that little or no recovery was obtained above or below the pH range described above $(8.4-9.5)$. However, with both galactose and xylose, recoveries increased with an increase in $\mathrm{pH}$. The maximum recoveries for galactose and xylose occurred at a pH of 11.5. The recoveries reported in Table VIII are only qualitative since: no precautions were taken to avoid iodine evaporation (operations performed in beakers to facilitate $\mathrm{pH}$ measurements); loss of sample on electrodes; and samples were only carried out in duplicate. However, the conditions required to obtain maximum recoveries were repeated with appropriate precautions such as, utilizing stoppered 
TABLE VIII

$\mathrm{pH}$ Range for maximum recovery

\begin{tabular}{lcl}
\hline Sugar & $\begin{array}{c}\text { Recovery } \\
\%\end{array}$ & pH range \\
\hline Glucose & 90 & 8.4 to 9.5 \\
Galactose & 92 & 11 to 12 \\
Xylose & 98 & 12.1 \\
\hline
\end{tabular}


flasks and the solutions were kept in the dark during the reaction time and after the addition of potassium iodide. The recovery studies were performed at three different levels for each sugar and the results reported in Table IX are the average of five determinations.

The results in Table IX indicate that the deviation in titrations was always less than \pm .20 milliliters. Glucose was determined with an accuracy of $\pm 3 \%$. At low levels of galactose ( $1 \mathrm{mg}$ per $\mathrm{ml}$ ) the exror reached a maximum of $-9 \%$. This could have resulted by a change in basicity due to the fact that 5.0-ml aliquots of sample were utilized. The maximum amount of error one could expect, otherwise, for all sugars is $\pm 6 \%$. However, in most cases, the per cent error is much less as illustrated in Table IX. The only solution that requires standardization is the sodium th. sulfate and a complete determination considering pipetting, reaction time, and titrating can be performed in approximately 45 minutes. 


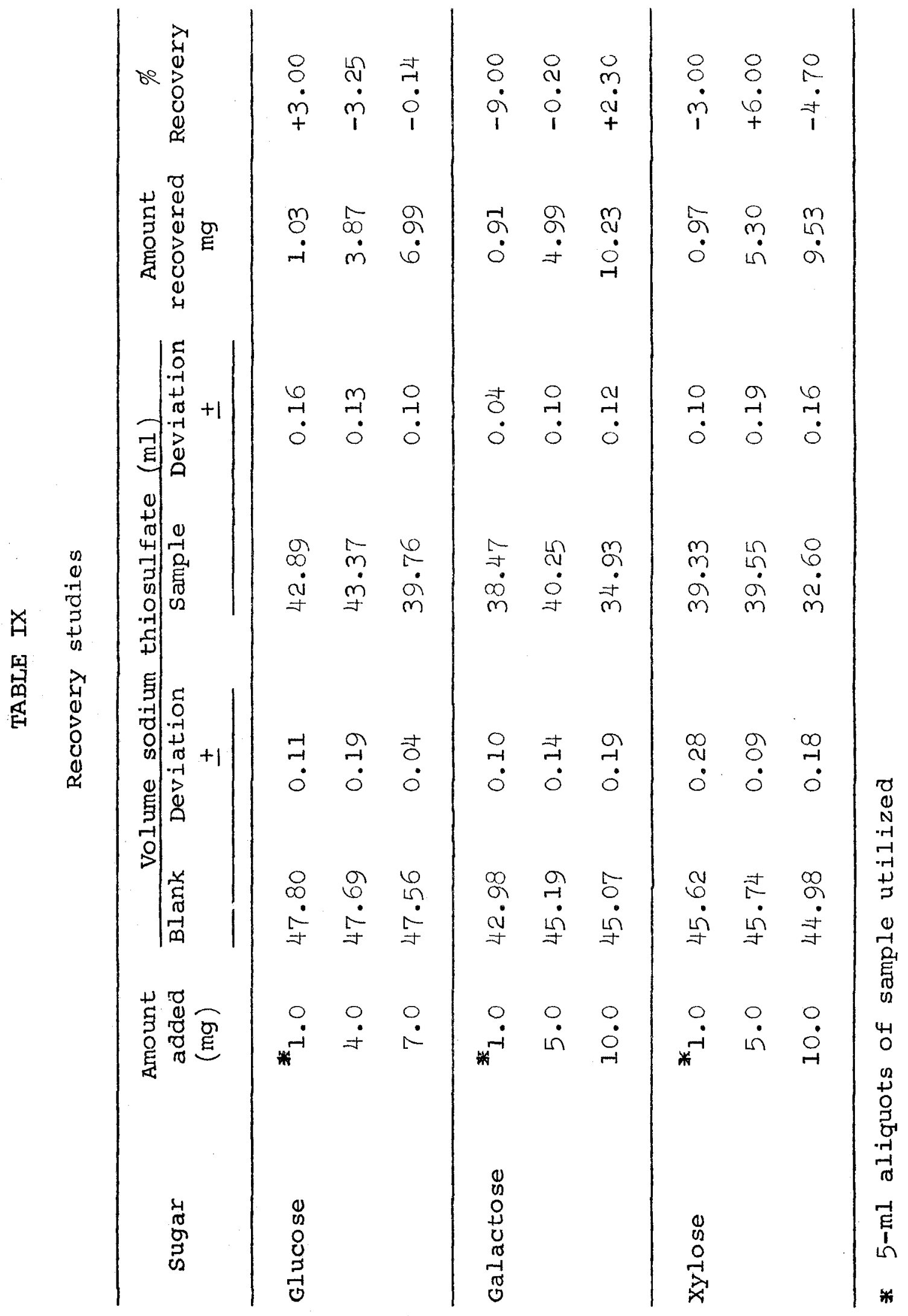




\section{CHAPTER IV}

\section{SUMMARY AND CONCLUSIONS}

I have outlined a procedure, based on the Tollens naphthoresorcinol reaction for the quantitative determination of total and conjugated glucuronic acid in pure and biological systems. The procedure is six times more sensitive than Fishman's method and eight times more sensitive than Nir's method. The precision of the MNR procedure in serum and urine is $\pm 0.3 \mu \mathrm{g}$ per $3.0 \mathrm{ml}$ (maximum) and the error limits in the optimum concentration range are $\pm 5 \%$. The method provides increased accuracy due to the selective elimination of the glucose interference by glucose oxidase and specific degradation of free glucuronic acid for the determination of conjugated glucuronic acid. The procedure is flexible and not as susceptible to changes due to variations in sample handling as are other procedures (62). The reagent is stable for a period of a week. The procedure is reproducible and very little change occurs in the results from various MNR preparations and matrices under investigation. The time required for a complete analysis is four hours. This study clarifies the accuracy and reproducibility of the naphthoresorcinol reagent which 78 
seems to be neglected in previous work. The molar absorptivity of the reagent under the MNR conditions is $30.1 \times 10^{3}$ and $16.5 \times 10^{3}$ depending on the heating period. The optimum concentration for the MNR procedure at $90 \mathrm{~min}$ and $30 \mathrm{~min}$ heating are 3.5 to $16 \mu \mathrm{g}$ per $3.0 \mathrm{ml}$ and 5 to $25 \mu \mathrm{g}$ per $3.0 \mathrm{ml}$, respectively. As little as $0.25-\mathrm{ml}$ samples of serum can be analyzed by this procedure by the method of standard addition described earlier in the text. It is suggested, however, that the lower concentration limit be maintained at $1 \mu \mathrm{g}$ per $\mathrm{ml}$. Therefore, one can utilize $1.0,0.5$, and $0.25-\mathrm{ml}$ samples depending on the availability of sample and final concentration of glucuronic acid being determined.

$\mathrm{N}$-Bromosuccinimide has been employed as a reagent for the quantitative determination of glucose, galactose, and xylose in pure solutions. The reactions are carried out at room temperature for 15 minutes. The errors involved are less than $\pm 6 \%$ at the milligram level. The time required for a complete determination is 45 minutes and the only standard solution required is sodium thiosulfate. 
1. West, E. S., and Todd, W. R., in Textbook of Biochemistry and Ed., The MacMillan Company, New York, 1955, p. 399.

2. Marsh, C. A., in Glucuronic Acid Edited by Dutton, G. J., Academic Press Inc., New York, 1966, p. 140 155 .

3. Thibert, R. J., Ph.D. Dissertation, wayne state University, Detroit, Michigan, 1958, p. 4.

4. White, A., Handler, P., Smith, E. I., and Stetten, Jr., D., in Principles of Biochemistry, McGraw-Hill Book Company Inc., New York, 1954, p. 808.

5. Asboe-Hansen(ed), in Connective Tissue in Health and Disease, Ajner Munksgaard, Publisher, 1954, p. 251, 239.

6. Marsh, C. A., in Glucuronic acid Edited by Dutton, G. J., Academic Press Inc., New York, 1966, p. 458.

7. Stevenson, H. I., and Dutton, G. J., Biochem. J., 82, 330 (1962).

8. Berliner, D. I., and Dougherty, T. F., Ann. N.Y. Acad. Sci., 88, 14 (1960).

9. Hartiola, K. J. W., and Pulkkinen, M. O., Ann. Acad. Sci. Fennicae Ser., Av 106 (12) (1964).

10. Nimi, T., Nagoya Shiritsu Daigaku Igakkai Zasshi, 15, $657,(1965)$.

11. Vest, M. F., and Fritz, E., J. Clin. Pathol., 14, $482(1961)$.

12. Hsia, D. Y-Y., Dowben, R. M., Shaw, R., and Grossman, A., Nature, 187, 693 (1960). 
13. Jondorf, W. R., Maickel, R. P., and Brodie, B. B., Federation Proc., 18, 407 and 418 (1959).

14. Ostrow, J. D., J. Lab. Clin. Med., 62, 998 (1963).

15. Lester, R., and Schmid, R., J. Clin. Invest., 44 , 722 (1965).

16. Fog, J., and Jellum, E., Nature, 198, 88 (1963).

17. Moscowitz, A., Krueger, W. C., Kay, I. T., Skewes, C., and Bruckenstein, S., Proc. Natl. Acad. Sci. U.S., 52, 1190 (1964).

18. Toda, H., Seni-i Gakkaishi, 16, 719 (1960).

19. Anderson, D. M. W., Talanta, 2, 73 (1959).

20. Tomoda, M., Yakugaku Zasshi, 80, 1696 (1960).

21. Tomada, M., Kyoritsu Yakka Daigaku Kenkyu Nempo, 617, $20(1961 / 2)$

22. Ishidate, M., and Shimozawa, T., J. Pharm. Soc. Japan, 64, $53(1944)$.

23. Wiley, R. C., Tauqkoli, M., and Moore, M. D., Proc. Am. Soc. Hort. Sci., 89, 34 (1966).

24. Perry, M. B., and Hullyalkar, P. K., Can. J. Biochem., $43(5), 573(1965)$.

25. Thibert, R. J., and Boyle, A. J., Talanta, 7, 175 (1961).

26. Miettinen, T., Ryhunen, V., and Salomou, H., Ann. Med. Exptls. Biol. Fennioe (Helsinki), 35, 173 (1957).

27. Akashi, M., Fukuoka Igaku Zassi, 48, 2112 (1957).

28. Momose, T., Ueda, Y., Yoshinaga, M., Masui, J., and Nagasaki, M., Yakugaku Zasshi, 78, 1064 (1958). 
29. Shimamura, T., Shinshu Med. I., 6, 371 (1957).

30. Cornillot, P., clin. Chim. Acta, I, 42 (1960).

31. Mosher, R. E., clin. Chem., 8, 378 (1962).

32. Wagner, w., Anal. Chim. Acta, 29, 227 (1963).

33. Nir, I., Anal. Biochem., 8, 20 (1964).

34. Hoffman, P., Linker, A., and Meyer, K., Science, 124, 1252 (1956).

35. Ishidate, M., Takitani, S., and Nakajima, T., Yakugaku Zasshi, 79, 843 (1959).

36. Johnson, s., and Samuelson, 0., Anal. Chim. Acta, 36, 1 (1966).

37. Bownes, J. M., Biochem. ․, 67, 295 (1957).

38. Gregory, J. D., Arch. Biochem. Biophys., 89, 157 (1960).

39. Galambos, J. T., and Mccain, J. R., Anal. Biochem., 19, 119 (1967).

40. Galambos, J. T., and McCain, J. R., Anal. Biochem., 19, 133 (1967).

41. Yuki, H., and Fishman, W. H., Biochim. Biophys. Acta, 69, 576 (1963).

42. Bitter, T., and Muir, H. M., Anal. Biochem., 4, 330 (1962).

43. Rafalowicz, A., Med. Doswiadczalna Mickrobiol., 14, 263 (1962).

44. Balazs, E. A., Bernsten, K. O., Karossa, J., and Swann, D. A., Anal. Biochem., 12, 547 (1965).

45. Anderson, D. M. W., and Garbutt, S., Anal. Chim. Acta, 29, $31(1963)$. 
46. Helbert, J. R., and Brown, K. D., Anal. Chem., 28, 1098 (1956).

47. Helbert, J. R., and Brown, K. D., Anal. Chem., 33, 1610 (1961).

48. Haug, A., and Larsen, B., Acta Chem. Scand., 16, 1908 (1962).

49. Shinriki, N., and Nambara, T., Yakugaku Zasshi, 83, 322 (1963).

50. Kawabata, H., Tomioka, S., and Umeno, K., Yakugaku Zasshi, 77, 767 (1957).

51. Bath, I. H., Analyst, 83, 451 (1958).

52. Zitko, V., Rosik, J., and Vasatko, J., Chem. Zuesti, 15, 890 (1961).

53. Lindh, N. O., Arkiv. Kemi, 10, 569 (1957).

54. Yamanaka, T., Asai, S., and Aoki, J., Yakuzaigaku, 22, 60 (1962).

55. Dubois, M., Gilles, K. A., Hamilton, J. K., Rebers, P. A., and Smith, F., Anal. Chem., 28, 350 (1956).

56. Dische, z., in Methods in Carbohydrate Chemistry Edited by Whistler, R. L., and Wolfromm, M. L., Academic Press, New York, 1962, p. 478.

57. Tollens, B., and Rorive, F., Ber., 41, 1783 (1908).

58. Maughan, G. B., Evelyn, K. A., and Browne, J. S. I., I. Biol. Chem., 126, 567 (1938).

59. Heyns, K., and Kelch, C., Z. Anal. Chem., 139, 339 (1953).

60. Hanson, W. F., Mills, G. T., and Williams, R. T., Biochem. J., 38, 274 (1944). 
61. Fishman, W. H., Smith, M., Thompson, D. B., Bonner, C. D., Kasdon, S. C., and Homberger, F., J. Clin. Invest., 30, 685 (1951).

62. Fishman, W. H. and Green, s., I. Biol. Chem., 215, 527 (1955).

63. Guerrero, A. H., and Williams, R. T., Nature, 161, 930 (1948).

64. Overend, W. G., Shafizadeh, F., and Stacey, M., J. Chem. Soc., p. 1487 (1951).

65. Heyns, K., and Beck, M., Chem. Ber. 20, 2443 (1957).

66. Momose, T., Ueda, Y., and Iwasaki, M., Chem. Pharm. Bull. (Tokyo), 10, 546 (1962).

67. Momose, T., Ueda, Y., and Iwasaki, M., Chem. Pharm. Bull. (Tokyo), 10, 633 (1962).

68. Nozaki, Y., Yakugaku Zasshi, 64, 9 (1944).

69. Artz, N. E., and Osman, E. M., in Biochemistry of Glucuronic Acid, Academic Press, New York, 1950, p. 6.

70. Tamura, Z., Nakajima, T., Tanaka, M., and Miyake, T., Bunseki Kagaku, 11, 1279 (1962).

71. Yuki, H., and Fishman, W. H., Biochim. Biophys. Acta, 74, 302 (1963).

72. Tamura, T., Seikagaku, 32, 790 (1960).

73. Tiakahashi, H., Nipoon Shonika Gakukai Zasshi, 65, 661 (1961).

74. Agostino, S. D., and Maddaluno, R., Aggiorn. Pediat., 15 (12), 565 (1964).

75. Nimi, T., Nagoya Shinitsu Daigaku Igakkai Zasshi, 15, (4), 657 (1965). 
76. Marsh, C. A., in Glucuronic Acid Edited by Dutton, G. J., Academic Press Inc., New York, 1966, p. 117 .

77. Kakinuma, S., J. Pharm. Soc. Japan, 59, 635 (1939).

78. Fashena, G., and Stiff, H., J. Biol. Chem., 137, 21 $(1941)$.

79. Kakinuma, S., J. Pharm. Soc. Japan, 60, 424 (1940).

80. Saltzman, A., Caraway, W. T., and Beck, I. A., Metabolism, Clin. and Exp., 3, 11 (1954).

81. Bonsenes, R. W. and Taussky, H. H., J. Biol. Chem., 158,581 (1945).

82. Varley, H., Practical Clinical Biochemistry. 4th Ed. Interscience Books Inc., New York, 1967, p. 199.

83. Aryes, H. G., Anal. Chem., 21, 652 (1949).

84. Fishman, W. H., Green, S., and Anstiss, C., Biochim. Biophys. Acta, 62, 574 (1962).

85. Litwack, G., Experimental biochemistry, John Wiley and Son Inc., New York, 1960, p. 44.

86. Sadahiro, R., Hinohara, Y., and Yamamoto A., J. Biochem., 57, 815 (1965).

87. Takabayashi, H., Nippon Syokakibyokai Zasshi, 55, 22 (1956).

88. Thibert, R. J., Ph.D. Dissertation, wayne state University, Detroit, Michigan, 1958, p. 51.

89. ziegler, K., Spath, A., Schaaf, E., Schumann, W., and Winkelman, E., Ann., 551, 80-119 (1942).

90. Djerassi, c., Chem. Revs. 43, 271 (1948).

91. Waugh, T. D., in Technical Bulletin, Arapahoe Chemicals Inc., Boulder, Colorado, 1951.

92. Horner, L., and Winkelmann, E. H., Angew. Chem., 71, 349 (1959). 
93. Thibert, R. J., and Sarwar, M., Mikrochim. Acta, 259 (1969). 
Born:

November 24, 1944; Casarsa, Udine, Italy. Son of Mr. and Mrs. P. Mazzuchin.

Primary School:

st. Alphonsus, Sudbury, Ontario, Canada.

Secondary School:

St. Charles College, Sudbury, Ontario, Canada.

University:

University of Windsor, Windsor, Ontario, Canada.

Degrees: B.Sc. in Chemistry - 1966.

M.Sc. in Analytical Chemistry - 1968.

Awards:

Province of Ontario Graduate Fellowship (1967 - 70).

Married:

To Dale Ann Orange, B.A., August 7, 1967.

Professional Societies:

Chemical Institute of vanada.

American Chemical Society.

Publications :

1. Study of sugars with cysteine-sulfuric acid reagents, Thibert, R. J., and Mazzuchin, A., Can. J. Biochem., 47, 203 (1969). 